Shveta Malhotra and Stephen G. Lomber

J Neurophysiol 97:26-43, 2007. First published Oct 11, 2006; doi:10.1152/jn.00720.2006

You might find this additional information useful...

This article cites 95 articles, 32 of which you can access free at: http://jn.physiology.org/cgi/content/full/97/1/26\#BIBL

Updated information and services including high-resolution figures, can be found at: http://jn.physiology.org/cgi/content/full/97/1/26

Additional material and information about Journal of Neurophysiology can be found at: http://www.the-aps.org/publications/jn

This information is current as of August 20, 2007. 


\title{
Sound Localization During Homotopic and Heterotopic Bilateral Cooling Deactivation of Primary and Nonprimary Auditory Cortical Areas in the Cat
}

\author{
Shveta Malhotra ${ }^{1,2}$ and Stephen G. Lomber ${ }^{2,1}$ \\ ${ }^{1}$ School of Behavioral and Brain Sciences, The University of Texas at Dallas, Richardson, Texas; and ${ }^{2}$ Centre for Brain and Mind, \\ Department of Physiology and Pharmacology and Department of Psychology, University of Western Ontario, London, Ontario, Canada
}

Submitted 13 July 2006; accepted in final form 8 October 2006

Malhotra S, Lomber SG. Sound localization during homotopic and heterotopic bilateral cooling deactivation of primary and nonprimary auditory cortical areas in the cat. J Neurophysiol 97: 26-43, 2007. First published October 11, 2006; doi:10.1152/jn.00720.2006. Although the contributions of primary auditory cortex (AI) to sound localization have been extensively studied in a large number of mammals, little is known of the contributions of nonprimary auditory cortex to sound localization. Therefore the purpose of this study was to examine the contributions of both primary and all the recognized regions of acoustically responsive nonprimary auditory cortex to sound localization during both bilateral and unilateral reversible deactivation. The cats learned to make an orienting response (head movement and approach) to a $100-\mathrm{ms}$ broad-band noise stimulus emitted from a central speaker or one of 12 peripheral sites (located in front of the animal, from left $90^{\circ}$ to right $90^{\circ}$, at $15^{\circ}$ intervals) along the horizontal plane after attending to a central visual stimulus. Twenty-one cats had one or two bilateral pairs of cryoloops chronically implanted over one of ten regions of auditory cortex. We examined AI [which included the dorsal zone (DZ)], the three other tonotopic fields [anterior auditory field (AAF), posterior auditory field (PAF), ventral posterior auditory field (VPAF)], as well as six nontonotopic regions that included second auditory cortex (AII), the anterior ectosylvian sulcus (AES), the insular (IN) region, the temporal (T) region [which included the ventral auditory field (VAF)], the dorsal posterior ectosylvian (dPE) gyrus [which included the intermediate posterior ectosylvian (iPE) gyrus], and the ventral posterior ectosylvian (vPE) gyrus. In accord with earlier studies, unilateral deactivation of AI/DZ caused sound localization deficits in the contralateral field. Bilateral deactivation of $\mathrm{AI} / \mathrm{DZ}$ resulted in bilateral sound localization deficits throughout the $180^{\circ}$ field examined. Of the three other tonotopically organized fields, only deactivation of PAF resulted in sound localization deficits. These deficits were virtually identical to the unilateral and bilateral deactivation results obtained during AI/DZ deactivation. Of the six nontonotopic regions examined, only deactivation of AES resulted in sound localization deficits in the contralateral hemifield during unilateral deactivation. Although bilateral deactivation of $\mathrm{AI} / \mathrm{DZ}, \mathrm{PAF}$, or AES resulted in profound sound localization deficits throughout the entire field, the cats were generally able to orient toward the hemifield that contained the acoustic stimulus, but not accurately identify the location of the stimulus. Neither unilateral nor bilateral deactivation of areas AAF, VPAF, AII, IN, T, $\mathrm{dPE}$, nor vPE had any effect on the sound localization task. Finally, bilateral heterotopic deactivations of AI/DZ, PAF, or AES yielded deficits that were as profound as bilateral homotopic cooling of any of these sites. The fact that deactivation of any one region (AI/DZ, PAF, or AES) was sufficient to produce a deficit indicated that normal function of all three regions was necessary for normal sound localization. Neither unilateral nor bilateral deactivation of AI/DZ, PAF, or AES affected the accurate localization of a visual target. The results

Address for reprint requests and other correspondence: S. G. Lomber, Centre for Brain and Mind, Robarts Research Institute, University of Western Ontario, 100 Perth Drive, London, Ontario N6A 5K8, Canada (E-mail: steve. lomber@uwo.ca). suggest that hemispheric deactivations contribute independently to sound localization deficits.

\section{N T R O D U C T I O N}

For any sound source, two fundamental tasks that the auditory system must accomplish are to determine the location of the sound source and to assign meaning to the sound (i.e., determine what the sound is; Rauschecker 1998). For most mammals, the ability to localize a sound in space plays a vital role in the detection and tracking of prey and the avoidance of predators. Revealing the processes and neural substrates that "create" and manipulate auditory space in the brain continues to be a persistent challenge (Middlebrooks et al. 2002). In intact animals, sound localization involves multiple sites in the brain stem, midbrain, thalamus, and cortex (Jenkins and Masterton 1982; Masterton et al. 1967, 1968; Thompson and Masterton 1978). Therefore although we consider it necessary for the auditory system to work as a whole to produce a rather complex behavior, like sound localization, it is unlikely that the contribution of each component, or subcomponents, is the same.

Sound localization has been examined in many species using a variety of behavioral testing techniques. With respect to examining the contributions of the cerebral cortex to sound localization, virtually all previous investigations either examined the contributions of auditory cortex as a whole or considered only the contributions of primary auditory cortex (AI). For example, in mammals with highly developed cerebral cortices, large bilateral cortical ablations encompassing most or all of acoustically responsive cortex in cats (Neff 1968; Neff et al. 1956; Strominger 1969a,b; Thompson and Welker 1963), ferrets (Kavanagh and Kelly 1987), opossums (Ravizza and Masterton 1972), dogs (Girden 1939; Heffner 1978), old-world monkeys (Heffner 1997; Heffner and Heffner 1990), and new-world monkeys (Ravizza and Diamond 1974) result in sound localization deficits throughout the entire field. Furthermore, ablations restricted to AI also result in spatial localization deficits within the contralateral field after unilateral ablations and throughout the entire field after bilateral ablations. Sound localization deficits after AI ablations were previously identified in cats (Jenkins and Merzenich 1984; Masterton and Diamond 1964; Riss 1959; Strominger 1969a), ferrets (Kavanagh and Kelly 1987), new-world monkeys (Thompson and

\footnotetext{
The costs of publication of this article were defrayed in part by the payment of page charges. The article must therefore be hereby marked "advertisement" in accordance with 18 U.S.C. Section 1734 solely to indicate this fact.
} 


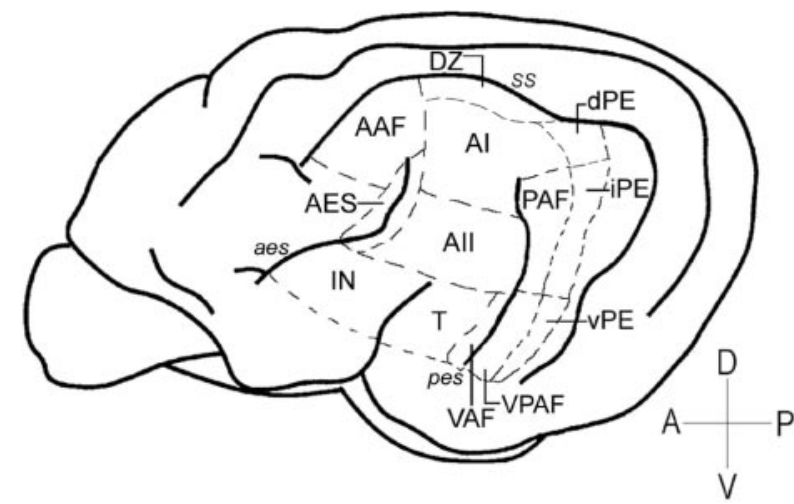

FIG. 1. Lateral view of the left hemisphere of cat cerebral cortex showing the positions of the loci examined in this study. Top is dorsal. Abbreviations: AI, primary auditory cortex; AII, second auditory cortex; AAF, anterior auditory field; AES, anterior ectosylvian sulcus; dPE, dorsal posterior ectosylvian gyrus; DZ, dorsal zone of auditory cortex; IN, insular region; iPE, intermediate posterior ectosylvian gyrus; PAF, posterior auditory field; PE, posterior ectosylvian; pes, posterior ectosylvian sulcus; ss, suprasylvian sulcus; $\mathrm{T}$, temporal region; VAF, ventral auditory field; VPAF, ventral posterior auditory field; vPE, ventral posterior ectosylvian gyrus. In subsequent figures, small versions of this schematic are used to indicate which site was deactivated. (Compiled from Clascá et al. 1997; Read et al. 2002; Reale and Imig 1980; Ribaupierre 1997; Tian and Rauschecker 1998.)

Cortez 1983), and old-world monkeys (Heffner and Masterton 1975; Wegener 1964).

Although the presence of multiple, nonprimary auditory cortical areas has been known for over half a century (Phillips et al. 1991; Woolsey and Walzl 1942), most auditory cortical research has focused on the AI. Only two studies have attempted to compare the contributions of various nonprimary regions of auditory cortex to sound localization and both of these studies were in the cat (Malhotra et al. 2004; Strominger 1969a). Strominger (1969a) examined large bilateral lesions of nonprimary auditory areas and Malhotra et al. (2004) examined unilateral deactivation of predominantly nonacoustic areas and some nonprimary auditory areas.

On a behavioral level, no previous studies examined the individual contributions of each region of nonprimary auditory cortex to sound localization. There are 13 known regions of acoustically responsive cortex in the cat (Fig. 1). Therefore the goal of the present study was to determine the contributions of the different regions of cat nonprimary auditory cortex to sound localization during bilateral deactivation. Specifically, we sought to test the hypothesis that in addition to AI, specific regions of nonprimary auditory cortex should also be involved in accurate sound localization behavior. We used orienting to an acoustic stimulus as a behavioral index and examined performance before, during, and after both unilateral and bilateral reversible cooling deactivation of each cortical locus (Lomber 1999). Overall we identified that unilateral and bilateral deactivation of areas $\mathrm{AI} /$ dorsal zone of auditory cortex (DZ), anterior ectosylvian sulcus (AES), or posterior auditory field (PAF) in auditory cortex all produce sound localization deficits without accompanying visual or motor deficits.

\section{METHODS}

Twenty-one mature ( $>6$ mo old) domestic cats (Table 1) were obtained from a commercial laboratory animal breeding facility (Liberty Labs, Waverly, NY) and housed in a colony environment with unlimited access to water. Food intake was restricted to the behavioral training/testing sessions and to $1 \mathrm{~h}$ at the conclusion of each day, when the animals had free access to dry cat food (Purina cat chow). All procedures were conducted in accordance with the National Research Council's Guidelines for the Care and Use of Mammals in Neuroscience and Behavioral Research (2003) and with the approval of the Animal Care and Use Committees of the University of Texas at Dallas and the University of Western Ontario.

In each animal, after all behavioral training was complete, cooling loops were bilaterally implanted over one or two auditory cortical loci. After cryoloop implantation, performance on the task was tested while all cortical loci were warm $\left(37-38^{\circ} \mathrm{C}\right)$ and active and while each region was both unilaterally or bilaterally cooled and deactivated. Each of the loci (Fig. 1) was examined in at least three cats (Table 1). Data from four of the 21 cats (Cats 1-4) appeared in an earlier publication (Malhotra et al. 2004), including unilateral deactivation data from the four tonotopically organized regions and second auditory cortex (AII).

\section{Apparatus and stimuli}

Training was conducted in an orienting arena that allowed for the presentation of either acoustic or visual stimuli. The apparatus (Fig. 2) was a semicircular arena (diameter $90 \mathrm{~cm}$ ) that consisted of 13 pairs of miniature speakers and red, 2-V (DC) light-emitting diodes (LEDs). The speakers (Kobitone part \#25RF006; Mouser Electronics, Mansfield, TX) were $2.5 \mathrm{~cm}$ in diameter with a frequency response ranging from $800 \mathrm{~Hz}$ to $5 \mathrm{kHz}$. The speaker/LED combinations were mounted $15^{\circ}$ apart along $180^{\circ}$ of the azimuthal plane. The pairs were located $45 \mathrm{~cm}$ from the animal's start position and positioned at cat's eye level. A food reward tray was located beneath each speaker/LED pair and was manually loaded after each behavioral response. The speakers emitted broad-band noise bursts (100 ms in duration). Before any training or testing, the loudspeakers were matched in intensity within $\pm 1 \mathrm{~dB}$ for $1 / 3$-octave frequency bands between $800 \mathrm{~Hz}$ and 5 $\mathrm{kHz}$ using a 1/3-octave equalizer in a manner similar to that reported by Kavanagh and Kelly (1987).

TABLE 1. Bilaterally implanted loci in each of the 21 experimental subjects

\begin{tabular}{|c|c|c|c|c|c|c|c|c|c|c|}
\hline \multirow[b]{3}{*}{ Cat } & \multicolumn{10}{|c|}{ Regions of Acoustically Responsive Cortex } \\
\hline & \multicolumn{4}{|c|}{ Tontotopic Areas } & \multicolumn{6}{|c|}{ Nontonotopic Areas } \\
\hline & AI & PAF & AAF & VPAF & AES & AII & IN & $\mathrm{T}$ & $\mathrm{dPE}$ & vPE \\
\hline 1 & & X & & & & $X$ & & & & \\
\hline 2 & & $X$ & $X$ & & & & & & & \\
\hline 3 & & $X$ & X & & & & & & & \\
\hline 4 & $X$ & & & $X$ & & & & & & \\
\hline 5 & & & & & $X$ & & & & & \\
\hline 6 & $X$ & & & $X$ & & & & & & \\
\hline 7 & & & & & $X$ & & & & & \\
\hline 8 & $\mathrm{X}$ & & & & $\mathrm{X}$ & & & & & \\
\hline 9 & $\mathrm{X}$ & $\mathrm{X}$ & & & & & & & & \\
\hline 10 & & & & & & $\mathrm{X}$ & & & $\mathrm{X}$ & \\
\hline 11 & & & & & & & & & & $\mathrm{X}$ \\
\hline 12 & & $X$ & & & $X$ & & & & & \\
\hline 13 & & & & & & & & & & $X$ \\
\hline 14 & $\mathrm{X}$ & & & & & & & & $\mathrm{X}$ & \\
\hline 15 & & $X$ & $X$ & & & & & & & \\
\hline 16 & & $\mathrm{X}$ & $\mathrm{X}$ & & & & & & & \\
\hline 17 & & & & & & & $X$ & X & & \\
\hline 18 & & & & & & & & $X$ & $X$ & \\
\hline 19 & & & & & & $X$ & $X$ & & & \\
\hline 20 & & & & $X$ & & & $X$ & & & \\
\hline 21 & & & & & & & & X & & $X$ \\
\hline Cats & 5 & 7 & 4 & 3 & 4 & 3 & 3 & 3 & 3 & 3 \\
\hline
\end{tabular}




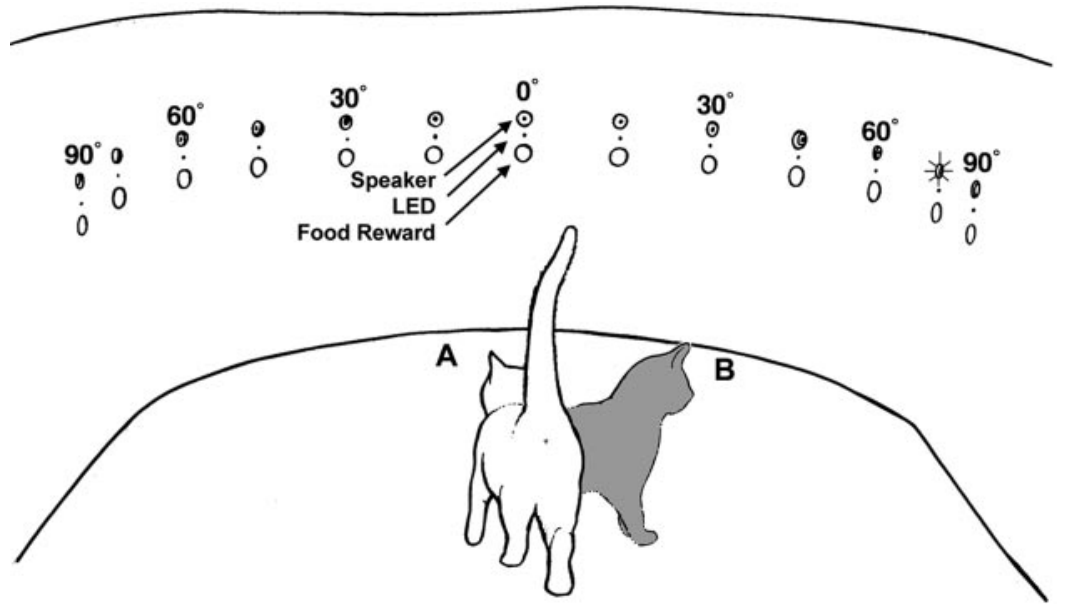

FIG. 2. Acoustic and visual orienting arena. A loudspeaker (top circle) and a light-emitting diode (LED, black dot) were located above a food reward locus (bottom circle) at each of 13 regularly spaced $\left(15^{\circ}\right)$ intervals (for sake of clarity, only $30^{\circ}$ intervals are labeled). $A$ : animal was first required to fixate on the central $\left(0^{\circ}\right)$ LED. $B$ : it then had to orient to, and approach, a secondary acoustic (100-ms broad-band noise) or visual (illumination of an LED) stimulus to receive a food reward.

Stimuli were generated using a Tucker-Davis (Alachua, FL) stimulus presentation workstation and SigGenRP stimulus design software. The calibration was conducted with a Larson Davis (Pleasant Grove, UT) model 800B sound level meter (SLM) with a 0.5-in. microphone placed equidistant between the L90 and R90 speakers. An A-weighting was used to determine the background noise level. For the experimental stimulus, we used broad-band noise bursts rather than pure tones because orienting responses to short broad-band noise bursts were previously identified to be much more accurate than responses to tones (Populin and Yin 1998). Testing was conducted in a sound-attenuated room lined in Sonex foam (Illbruck, Minneapolis, $\mathrm{MN})$. The normal background noise of the room was $58 \mathrm{~dB}(\mathrm{~A})$ and the broad-band noise burst stimulus was presented at $78 \mathrm{~dB}(\mathrm{~A})$. Training was conducted in a dimly lit room and ambient light levels $\left(23 \mathrm{~cd} / \mathrm{m}^{2}\right)$ were monitored using an Extech (Tampa, FL) datalogging light meter (model 401036).

Two individuals conducted the experiments: an experimenter and the animal handler. The experimenter controlled the stimulus presentation, recorded the behavioral responses, and viewed a video monitor that displayed images from a video camera that looked down on the apparatus and was used to determine the accuracy of the orienting response. The orienting response on each trial was determined by the experimenter's inspection of the trial on the video monitor. Cooling deactivation sessions were videotaped. The videotaped responses were reviewed when the experimenter was unable to accurately determine the orienting response during testing. The animal handler was responsible for positioning the animal in the center of the apparatus and was blind to the stimulus presentation sequence. In the early stages of behavioral training, the animal handler securely held the cat in position in the center of the apparatus during stimulus presentation. By the conclusion of training the cat merely positioned itself in the center of the apparatus and awaited presentation of the stimulus. Therefore the animal handler could not inadvertently provide cues to the cat by contact.

\section{Task and training}

After acclimation to the testing apparatus, each cat was pretrained to stand in the center of the arena and approach the illumination of the red LED at the $0^{\circ}$ position. A piece of low-incentive, dry cat chow was then presented from the reward tray below the stimulus. During training, the animal's attention was first attracted to the central LED. Then, the LED was extinguished and the sound was presented at one of the 12 peripheral speakers or the central speaker. After the animal approached the stimulus it received the moist food reward from the food tray below the speakers. The rapid and accurate turning of the head, or head and body, and accurate approach toward the locus of the acoustic stimulus constituted a correct orienting response. Any re- sponse other than a prompt direct approach to the appropriate stimulus was scored as incorrect. The cat was conditioned to approach the $0^{\circ}$ position when an acoustic stimulus could not be localized and receive the low-incentive food. Premature responses, or a lack of response, were not scored and went unrewarded. Twenty-eight trials formed a block, with each of the 12 peripheral positions tested twice and the central position tested four times. Five blocks of data were collected in each session for a total of 140 trials. Catch trials, where no target stimulus was presented, were randomly conducted. In a catch trial the cats were trained to approach the $0^{\circ}$ position and receive the lowincentive food. As a control, the animals were also trained to orient to a visual stimulus. For the visual task, testing procedures were identical, with the only difference being that the target stimulus consisted of a flashed red 2-V (DC) LED. During the final stages of training and during testing, behavioral procedures remained the same, although the cats wore a loose-fitting harness and a lightweight tether that supported the cooling tubes and microthermocouple wires. The tether, tubes, and wires were connected to a loop directly above the animal. Training was complete when a criterion performance level of $\geq 80 \%$ correct across the entire field was reached on two consecutive days. After the criterion was achieved, the stimuli were presented more than 100 times at each of the 12 peripheral positions examined.

\section{Surgical procedures}

Cooling loops were implanted after training was complete. Cryoloops were fabricated by shaping loops of 23-gauge stainless steel hypodermic tubing to conform to one of the ten areas examined (Lomber et al. 1999). Before surgery, all loops were sterilized with ethylene oxide gas. During the 24 -h period before cooling loop implantation, all cats were deprived of food and given dexamethasone [1.0 mg/kg, administered intramuscularly (im)]. Cannulation of the cephalic vein allowed administration of anesthetic and the infusion of fluids (2.5\% dextrose and half-strength lactated Ringer solution). Sodium pentobarbital (about $25 \mathrm{mg} / \mathrm{kg}$ to effect) was infused [intravenously (iv)] to induce general anesthesia. The animal was then placed in a stereotaxic apparatus and prepared for surgery using procedures described elsewhere (Lomber et al. 1999). A midline incision was made in the scalp and the temporalis muscles were detached medially and reflected laterally. Craniotomies were made over the desired regions and the dura was incised and reflected to expose the cerebrum. Cryoloops were secured to the skull by using stainless steel skull screws and dental acrylic.

\section{Cortical loci investigated}

We used reversible cooling deactivation (Lomber et al. 1999) to examine the contributions that ten individual regions of auditory 
cortex made to acoustically mediated orienting (Fig. 1). The positions of the different loci are described below.

TONOTOPICALLY ORGANIZED REGIONS. We examined four regions of tonotopically organized auditory cortex: the primary auditory cortex (AI), the posterior auditory field (PAF), the anterior auditory field (AAF), and the ventral posterior auditory field (VPAF). An AI loop was about $6 \mathrm{~mm}$ long and extended lengthwise across the middle ectosylvian gyrus, from the dorsal tip of the of the anterior ectosylvian sulcus to just posterior of the posterior ectosylvian sulcus (about A4-A10 ${ }^{1}$; Reale and Imig 1980; Fig. 1). Therefore these loops were intended to cool both AI and the dorsal zone (Middlebrooks and Zook 1983). Cryoloops were also placed on PAF (Phillips and Orman 1984; Reale and Imig 1980), located caudal and ventral to AI. Loops were approximately $6 \mathrm{~mm}$ long and extended from the anterior one third of the dorsal-posterior ectosylvian gyrus to the fundus of the dorsal half of the posterior ectosylvian (PE) sulcus. At this location, the PE sulcus is about $2.5 \mathrm{~mm}$ deep. The AAF (Knight 1977; Phillips and Irvine 1982; Reale and Imig 1980) cryoloops were about $6.5 \mathrm{~mm}$ long and were located on the crown of the anterior suprasylvian gyrus between A11 and A17.5. Loops about $8 \mathrm{~mm}$ long were also placed on VPAF. These loops extended from the anterior one third of the ventral PE gyrus and extended to the fundus of the dorsal PE sulcus. A heatshielding compound (\#SO-FH06 from Small Parts, Miami Lakes, FL) was also applied to the anterior side of the PAF and VPAF loops to keep the cooling deactivations localized to the posterior bank of the PE sulcus.

NONTONOTOPICALLY ORGANIZED REGIONS. We examined six regions of nontonotopically organized auditory cortex: the auditory field of the anterior ectosylvian sulcus (AES), the second auditory cortex (AII), the insular (IN) region, the temporal (T) region, the dorsal posterior ectosylvian (dPE) gyrus, and the ventral posterior ectosylvian (vPE) gyrus. The auditory field contained in the AES occupies a region at the posterior end of the anterior ectosylvian sulcus with the largest portion of the field located on the dorsal bank and fundus (Clarey and Irvine 1986; Meredith and Clemo 1989; Mucke et al. 1982). Loops about $6 \times 3 \mathrm{~mm}$ were placed in the posterior two thirds of the AES where both the auditory and visual representations are located (Rauschecker and Korte 1993). Therefore placement of the AES cooling loops was similar to loops implanted by others (Jiang et al. 2001, 2002). Loops about $6 \times 3 \mathrm{~mm}$ were placed on AII, which lies ventral to $\mathrm{AI}$ and extends between the anterior and posterior ectosylvian sulci (Reale and Imig 1980). The longest dimension of the loop extended anterior to posterior.

The insular (IN) region occupies a swath of cortex on the anterior sylvian gyrus, between the anterior ectosylvian and sylvian sulci. IN cortex is ventral to AII. Cooling loops $(6 \times 3 \mathrm{~mm})$ were placed lengthwise over the anterior sylvian gyrus. We defined the temporal (T) area as a band across the posterior sylvian gyrus from the sylvian sulcus, anteriorly, to a position about $2 \mathrm{~mm}$ anterior to the posterior ectosylvian sulcus. The region visible just anterior to the PE sulcus is the ventral auditory field (VAF; Reale and Imig 1980). Because of the small size of the VAF, the $5 \times 3$-mm cooling loops placed over area $\mathrm{T}$ were also expected to deactivate VAF.

On the PE gyrus, anatomical and electrophysiological investigations suggest that the gyrus contains three parallel and vertically oriented "belts" (Bowman and Olson 1988a,b; Reale and Imig 1980; Updyke 1986; Woolsey 1960). The anterior belt contains the two tonotopically organized regions previously described (PAF and VPAF). The middle belt is unimodal and responds to acoustic stimuli, but lacks a tonotopic organization (Bowman and Olson 1988a,b). This middle belt was previously further subdivided into dorsal (dPE), intermediate (iPE), and ventral (vPE) subdivisions based on cytoarchitecture and patterns of extrinsic connections (Winer 1992). The

\footnotetext{
${ }^{1}$ Stereotaxic coordinates are provided using the Horsley and Clarke (1908) system as described by Reinoso-Suárez (1961).
}

posterior belt along the entrance to the posterior suprasylvian sulcus contains both visually and acoustically responsive neurons (Bowman and Olson 1988a,b; Updyke 1986). In this study, we subdivided the central and posterior belts into dorsal and ventral halves and placed vertically oriented $3 \times 8$-mm cooling loops over each region. Therefore we expected to deactivate both areas dPE and iPE with the dPE loops and area vPE with the vPE loops (Fig. 1).

\section{Postsurgical procedures and implant care}

After cryoloop placement, the dura was replaced or Gelfilm (Upjohn Company, Kalamazoo, MI) was placed over the exposed cerebrum. With the exception of where the cooling tubes exited the skull, the previously removed bone piece was replaced. Additional skull screws and acrylic were applied to secure the cooling loop and bone pieces. Dermal incisions were closed with 3-0 silk sutures that were removed 7-10 days later. Buprenorphine analgesic $(0.01 \mathrm{mg} / \mathrm{kg}, \mathrm{im})$ was administered during the initial period after awakening. Decreasing doses of dexamethasone were administered over the next week and fluids [2.5\% dextrose and one-half strength lactated Ringer solution, $20 \mathrm{ml} / \mathrm{kg}$, subcutaneous (sc)] were infused as needed. The cats also received Ultra-pen (Hanford Pharmaceuticals, Syracuse, NY) systemic antibiotic (300,000 units, im) for $1 \mathrm{wk}$ to guard against infection. The skin surrounding the implant was inspected daily for any change in appearance and Panalog (Squibb, Princeton, NJ) antibiotic ointment was applied prophylactically as needed.

\section{Behavioral testing and cooling deactivation}

After cooling loop implantation and before any deactivations, baseline performance levels were quickly reestablished. A five-step testing paradigm was used with each step consisting of at least one block: 1) Baseline data were collected with all sites active. 2) Testing began while a site in the left hemisphere was cooled and deactivated. 3) Cooling of the homotopic site in the right hemisphere was then added to study the effects of bilateral deactivation. 4) The cooling of the left side was terminated and cortex was allowed to rewarm while the site in the right hemisphere remained deactivated. 5) Baseline levels were reestablished after cessation of cooling and reactivation of the right side. This procedure was also conducted in reverse order (right, bilateral, then left). Additional data were also collected while a single site was either unilaterally or bilaterally deactivated. In total, $\geq 24$ trials were collected at each target locus both before and after cooling deactivation and $\geq 48$ trials/locus were collected during each of the three cooling deactivation conditions.

Cooling deactivation of cortex in contact with the cryoloop was effected by pumping cold methanol through the lumen of the cryoloop tubing. Cryoloop temperature was monitored continuously by a microthermocouple attached to the union of the loop (Lomber et al. 1999), where the tubing comes together to form the loop. Cooling of cryoloops to $3 \pm 1{ }^{\circ} \mathrm{C}$ is sufficient to deactivate the full-thickness cortex in contact with the cryoloop (Lomber and Payne 2000). On the gyral surface the typical cryoloop has a resting temperature of $36^{\circ} \mathrm{C}$, whereas the typical sulcal loop has a resting temperature of $37^{\circ} \mathrm{C}$. During testing, the cats wore a harness and a tether that supported the cooling tubes and thermocouple wire. The harness did not restrict head or general movement of the cat. Each animal had one or two bilateral pairs of cryoloops (Table 1). The testing regime usually required 3-5 mo of daily testing.

For both orienting tasks we calculated percentage correct responses. Performance was assessed with a mixed ANOVA with one withinhemisphere variable (warm vs. cold; locus of cooling loop). Orienting responses were assessed with multifactor mixed ANOVA variables (warm vs. cold, azimuth, locus of cooling loop). The order of sessions was counterbalanced between areas (loops), functional states (active vs. deactivated), and hemispheres. When a difference was detected with the ANOVAs, we conducted follow-up within-subject $t$-test 
(Tukey test). In the RESULTS section, the $P$ value from the $t$-test is provided when the difference between variables was significant. If a cooling-induced deficit was significant, additional $t$-tests were performed to determine whether performance was different from chance ( $7.7 \%$ correct).

\section{Terminal procedures}

At completion of behavioral testing, nine cats were anesthetized (sodium pentobarbital, $25-30 \mathrm{mg} / \mathrm{kg}$, iv), small craniotomies were made, and we measured temperatures beneath the cooling loops to determine the deactivated region during cooling of the cryoloops to $3 \pm 1{ }^{\circ} \mathrm{C}$. The purpose of these measurements was to identify the position of the $20^{\circ} \mathrm{C}$ thermocline: the critical temperature below which neuronal activity is silenced is $20^{\circ} \mathrm{C}$ (Lomber et al. 1999). Positions between the $20^{\circ} \mathrm{C}$ thermocline and the cooling loop were at temperatures $<20^{\circ} \mathrm{C}$ and were silenced, whereas positions distal to the $20^{\circ} \mathrm{C}$ thermocline, relative to the cooling loop, were warmer than $20^{\circ} \mathrm{C}$ and partially or fully active. Cortical temperatures during cooling were measured simultaneously at four different coronal levels in the brain using multiple microthermocouples $(150 \mu \mathrm{m}$ in diameter) manufactured for us by Omega Engineering (Stamford, CT). The microthermocouples were first positioned and then the loop was cooled to several temperatures; $100-120$ sites were sampled at each of the coronal levels. This procedure ensured that temperature measurements for a given cryoloop temperature setting were taken at exactly the same sites in cortex. For each measurement, cortex was cooled for roughly $5 \mathrm{~min}$ before a recording being made, as occurred in the behavioral component of the study. This protocol was then repeated at multiple, sequentially sampled sets of sites. After completion of the mappings, the craniotomies were closed and each animal was allowed to recover from the anesthesia.

Two days after completion of the thermodynamic recording and/or all behavioral studies, every cat received a systemic iv injection of ${ }^{14} \mathrm{C}-2$ deoxyglucose (2DG, $100 \mu \mathrm{Ci} / \mathrm{kg}$ ), as described previously (Payne and Lomber 1999). During 2DG administration, the animals were fully conscious to maximize uptake. A venous catheter was inserted into a cephalic vein. The cats were comfortably restrained in a veterinary cat sack and the inlet and outlet tubes of the cryoloop(s) were connected to the cooling circuit. In each cat, a single loop was cooled or two loops (one in each hemisphere) over heterotopic loci were cooled. After temperature stabilization (about $5 \mathrm{~min}$ ) at $3 \pm 1{ }^{\circ} \mathrm{C}$, the first of four boluses of $25 \mu \mathrm{Ci} \mathrm{kg}{ }^{-1}$ of 2-deoxy-D-[U- $\left.{ }^{14} \mathrm{C}\right]$ glucose was administered. The remaining boluses were injected at 5 -min intervals. By $10 \mathrm{~min}$ after the final injection, heparin (2,000 units $/ \mathrm{kg}$, iv) and sodium nitrite ( $1 \mathrm{ml}$ of $0.1 \%$ solution, iv) were administered and the cat was deeply anesthetized with sodium pentobarbital (45 $\mathrm{mg} / \mathrm{kg}$, iv) and perfused with fixatives in accordance with the recommendations of the American Veterinary Medical Association Panel on Euthanasia (Beaver et al. 2001). The brain was quickly exposed (about $4 \mathrm{~min}$ ), removed from the skull, blocked, and photographed. The brain was coated with egg albumin and placed in methylbutane $\left(-35^{\circ} \mathrm{C}\right)$. After $30 \mathrm{~min}$, the brain was transferred to a $-80^{\circ} \mathrm{C}$ freezer for subsequent tissue processing.

The brains were sectioned in a cryostat $\left(-20^{\circ} \mathrm{C}\right)$ at $35 \mu \mathrm{m}$ and every fifth section was collected on coverslips. Hemispheres that contained cooled PAF, VPAF, IN, T, dPE, or vPE loops were cut in the horizontal plane, whereas all other hemispheres were cut in the coronal plane (Fig. 3). Dried sections were applied to X-ray film and processed using routine procedures (Payne and Lomber 1999). The extent of the deactivated area was then determined by delineating the region of decreased 2DG uptake. This region was then compared with the thermoclines determined in the thermodynamic mapping procedure. In all cases, both the thermodynamic mapping and metabolic map (2DG) were found to be in accord. Cooling-induced decreases in 2DG uptake are obvious (Payne and Lomber 1999) and require only imaging equipment to assay the gradients on the fringes of the deactivation. For these purposes we used an MCID Elite imaging analysis system (Imaging Research, St. Catherines, Ontario, Canada). The borders of the region of decreased 2DG uptake ( $>25 \%$ reduction) were determined by standardizing the brains with ${ }^{14} \mathrm{C}$ standards (Amersham, Arlington Heights, IL) and calibration curves (GonzalezLima 1992) and comparing the region with the similar site from a population of normal, nondeactivated brains that were not part of this study. The results from these analyses are provided in Fig. 3. Every fifth section was processed histochemically for the presence of cytochrome as previously done (Payne and Lomber 1996) and adjacent sections were stained using conventional methods for the presence of Nissl bodies or myelin.

\section{RES ULTS}

\section{Cortical cytoarchitecture}

For each region of the auditory cortex that was cooled, the cytoarchitecture of Nissl-stained sections was characteristic of healthy cortex (Kelly and Wong 1981; Rose 1949; Sanides and Hoffman 1969; Sousa-Pinto 1973). We were unable to find any evidence of physical damage, gliosis, or necrosis. In addition, no changes were identified in either myelin staining or cytochrome oxidase histochemistry. Therefore neither the presence of the cryoloops nor their repeated deactivation over several months changed the structure or long-term function of the ten cortical sites assayed.

\section{Cooling deactivation reconstructions}

Examples of the deactivation extents for each of the ten loci examined are illustrated in Fig. 3. The extent of the deactivation was determined from 2DG radiograms and confirmed using the thermodynamic map results from a subset of the animals. Regions showing greatly reduced 2DG uptake $(>25 \%$ decrease), compared with surrounding structures, are indicated in black on diagrams of the whole brain and in coronal or horizontal sections (Fig. 3). All regions of deactivation were highly circumscribed and extended beyond the perimeter of the loops by $1-1.5 \mathrm{~mm}$ and through all six layers of cortex. Loops inserted into the anterior ectosylvian sulcus (e.g., Fig. 3E) deactivated both banks of the sulcus, whereas PAF and VPAF loops (Fig. 3, $B$ and $D$ ) deactivated only the posterior bank of the posterior ectosylvian sulcus. Gyral loops deactivated exposed surfaces, although they could include cortex bounding the entrances to sulci (e.g., Fig. 3, $C$ and $H$ ). Detailed evaluations of the cooling deactivations for each cortical locus are provided with the behavioral results from cooling each site.

\section{Tonotopically organized regions}

EXTENT OF DEACTIVATIONS. AI (and DZ). A representative deactivation resulting from cooling of an AI/DZ cryoloop to $3 \pm 1{ }^{\circ} \mathrm{C}$ is illustrated in Fig. $3 A$. For all AI/DZ cryoloop coolings, the central region of the middle ectosylvian gyrus between the dorsal tips of the anterior and posterior ectosylvian sulci was deactivated. Medially, this region extended to the middle suprasylvian sulcus. The largest deactivations were from A2 to A12 and the smaller deactivations were from A4 to A10. The largest deactivations also included a small region of the dorsal sylvian gyrus. For each loop the deactivated region included the classically defined area AI (Reale and Imig 1980), the dorsal zone (Middlebrooks and Zook 1983), and the region 
A Primary Auditory Cortex (AI) and (DZ)

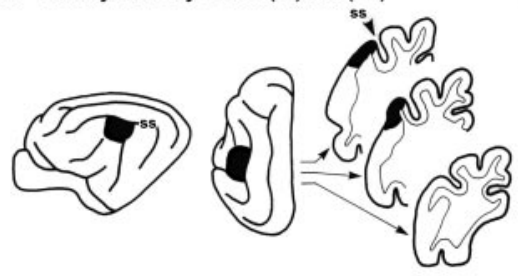

C Anterior Auditory Field (AAF)
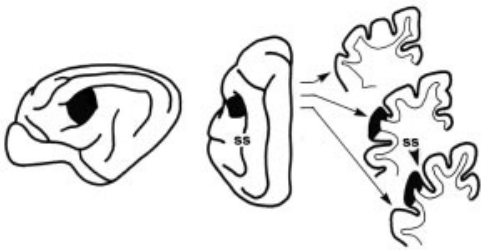

E Anterior Ectosylvian Sulcus (AES)
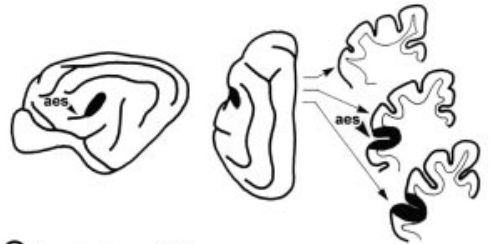

G Insular Area (IN)

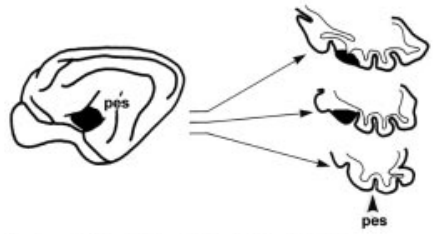

I dorsal Posterior Ectosylvian (dPE) gyrus and (iPE)

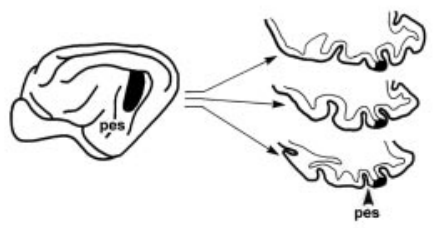

B Posterior Auditory Field (PAF)
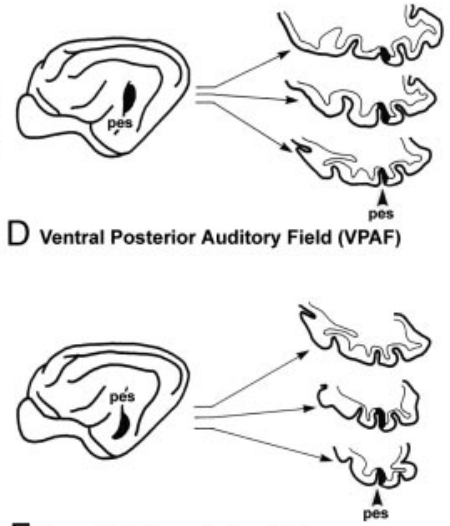

F Second Auditory Cortex (All)

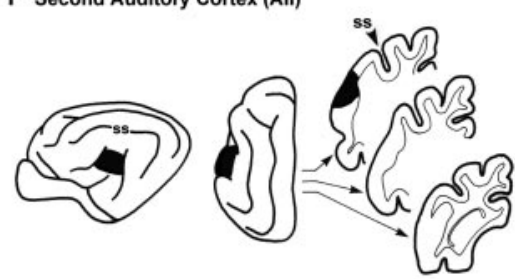

H Temporal (T) Area and (VAF)

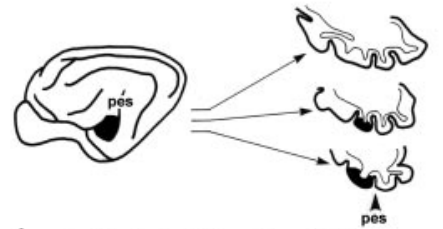

J ventral Posterior Ectosylvian (VPE) gyrus

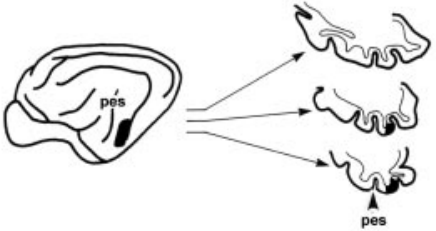

FIG. 3. Representative cooling deactivation reconstructions for the 10 cooling loop placements. $A, C, E, F$ : each reconstruction shows a lateral (left is anterior) view of the left hemisphere with 3 coronal sections in the vicinity of the deactivation locus. $B, D, G-J$ : deactivation reconstructions showing a lateral (left is anterior) view of the left hemisphere with 3 horizontal sections in the vicinity of the locus. Blackened region indicates the extent of cooling-induced deactivation, as assessed by severely reduced ${ }^{14} \mathrm{C}-2$ deoxyglucose (2DG) uptake ( $>25 \%$ reduction). These standardized drawings are adaptations from Reinoso-Suárez (1961). For abbreviations, see Fig. 1. previously described as the suprasylvian fringe (Beneyto et al. 1998; Niimi and Matsuoka 1979; Paula-Barbosa et al. 1975; Woolsey 1960).

$P A F$. For all deactivation extents of the PAF cryoloops, the regions included the anterior-dorsal posterior ectosylvian gyrus, just posterior to the PE sulcus (Fig. $3 B$ ). For the largest extents, the deactivation spread slightly more dorsally and posteriorly away from the PE sulcus. All deactivations extended down the posterior bank of the PE sulcus to the fundus (Fig. 3B). The deactivations did not include the anterior bank of the sulcus. Therefore all deactivated regions included all of area PAF or area P (Imig et al. 1982; Phillips and Orman 1984).

$A A F$. Cooling of any of the AAF cryoloops deactivated a large region of the anterior ectosylvian gyrus (Fig. 3C). All deactivations included the dorsal half of the lateral bank of the anterior suprasylvian sulcus and the dorsal half of the medial bank of the AES. The largest deactivations extended along the gyrus from A9 to A19, whereas the smaller deactivations extended from A10 to A18. The larger extents deactivated all of area AAF or area A, as defined by Knight (1977) and Reale and Imig (1980). Although the position of AAF is highly variable between animals, its posterior border is seldom caudal to A10 (Knight 1977). Therefore the smaller extents also deactivated all of area AAF.

$V P A F$. Cooling of the VPAF cryoloops deactivated a common region of the anterior-ventral $\mathrm{PE}$ gyrus, just posterior to the PE sulcus (Fig. 3D). In all cases the deactivation extended down the posterior bank of the PE sulcus to the fundus (Fig. $3 D$ ). The deactivation did not include the anterior bank of the sulcus. In the largest extents, the deactivation included more of the surface of the PE gyrus extending toward the posterior suprasylvian sulcus (Fig. 3D). In all cases, the deactivated region included all of area VP, as defined by Imig et al. (1982).

BEHAVIOR. Controls. Before AI/DZ cooling loop implantation, the cats were highly proficient at the acoustic spatial localization task $[92.9 \pm 2.3 \%$ correct across the 13 positions (mean \pm SE); Fig. 4Ai]. With the exception of the far peripheral positions (L90 and R90), performance was $>90 \%$ at each 


\section{A Controls}

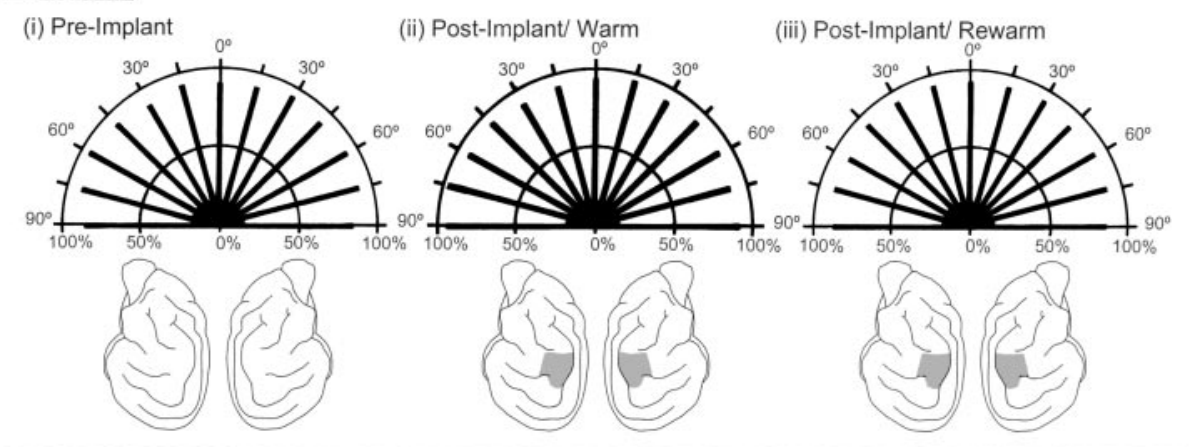

\section{B Deactivations}

(iv) Left

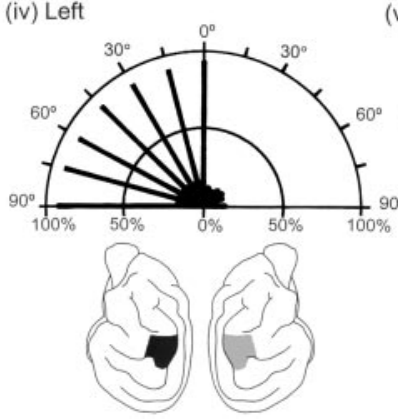

(v) Bilatera

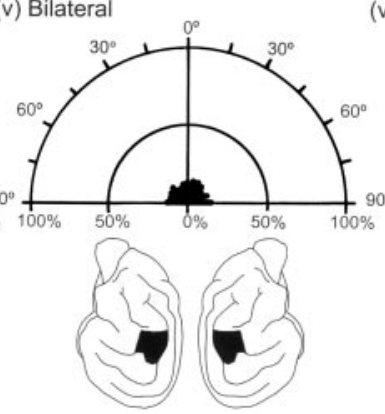

(vi) Right

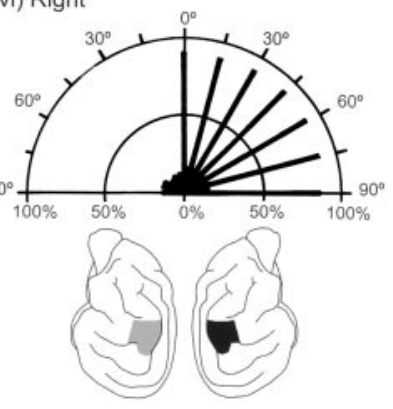

FIG. 4. Orienting responses to an acoustic stimulus during deactivation of AI (including the dorsal zone). Lateral view icons of the cat brain indicate the presence and position of a cryoloop (gray shading) and its operational status (black indicates loop was on and cortex was deactivated). In this and subsequent data graphs, the 2 concentric semicircles represent 50 and $100 \%$ correct response levels and the length of each bold line corresponds to the percentage of correct responses at each location tested. A: control data collected: (i) before $\mathrm{AI} / \mathrm{DZ}$ cryoloop implantation, (ii) after AI/DZ cryoloop implantation and before cooling in each testing session, and (iii) shortly after termination of cooling. $B$ : deactivation data collected: (iv) during cooling of left AI/DZ, (v) during bilateral cooling of $\mathrm{AI} / \mathrm{DZ}$, and (vi) during cooling of right $\mathrm{AI} / \mathrm{DZ}$. Note that unilateral deactivation of $\mathrm{AI} / \mathrm{DZ}$ caused sound localization deficits in the contralateral field with no impairments in the ipsilateral hemifield. Bilateral deactivation of $\mathrm{AI} / \mathrm{DZ}$ resulted in bilateral sound localization deficits throughout the tested field. Data summarized from 5 animals. locus (Fig. 4Ai). After cooling loop implantation (warm), orienting response accuracy to the acoustic stimuli was virtually identical to preimplant performance levels (compare Fig. $4 A, i$ and $i i$; Table 2). In fact, performance actually improved at the farmost peripheral positions as a consequence of the additional postimplant training. The similarities between the pre- and postimplant performance indicate that neither the surgical implantation of the cooling loops nor the continual presence of the loops interfered with accurate sound localization. Furthermore, accurate orienting performance to every position examined returned to normal levels after the daily termination of cooling (rewarm; compare Fig. 4A, ii and iii;
Table 2). The similarities between the warm and rewarm performances (Table 2) indicate that the repeated daily cooling of the cryoloops did not impair sound localization accuracy after rewarming of the cortex. Virtually identical control data were collected from the other three tonotopically organized areas (e.g., Figs. $5 A$ and $6 A$, PAF and AAF, respectively; Table 2 ).

Deactivations. Data collected during bilateral and unilateral deactivation of AI/DZ in five cats (Table 1) are summarized in Fig. 4. Unilateral cooling of the left AI/DZ cryoloop significantly reduced $(P<0.01)$ accurate orienting responses throughout the right (contracooled) hemifield from $92.3 \pm$

TABLE 2. Percentage correct orienting responses for the six conditions tested for each of the ten acoustic areas examined

\begin{tabular}{|c|c|c|c|c|c|c|c|}
\hline Region & Hemifield & Preimplant & Warm & Cool/Left & Cool/Right & Cool/Bilateral & Rewarm \\
\hline \multirow[t]{2}{*}{$A I($ and $D Z)$} & Left & $92.2 \pm 2.5 \%$ & $93.0 \pm 3.1 \%$ & $93.4 \pm 3.6 \%$ & $10.2 \pm 3.1 \%$ & $10.8 \pm 4.7 \%$ & $91.9 \pm 4.3 \%$ \\
\hline & Right & $93.6 \pm 2.9 \%$ & $92.3 \pm 2.8 \%$ & $11.7 \pm 3.6 \%$ & $91.9 \pm 2.5 \%$ & $11.6 \pm 4.3 \%$ & $91.0 \pm 4.1 \%$ \\
\hline \multirow[t]{2}{*}{ PAF } & Left & $93.0 \pm 3.3 \%$ & $92.1 \pm 3.6 \%$ & $93.2 \pm 1.7 \%$ & $11.5 \pm 1.9 \%$ & $8.7 \pm 3.3 \%$ & $91.7 \pm 3.3 \%$ \\
\hline & Right & $92.2 \pm 1.7 \%$ & $90.4 \pm 3.3 \%$ & $13.8 \pm 2.7 \%$ & $92.8 \pm 2.2 \%$ & $11.2 \pm 3.5 \%$ & $92.6 \pm 2.7 \%$ \\
\hline \multirow[t]{2}{*}{ AAF } & Left & $90.5 \pm 3.3 \%$ & $88.1 \pm 3.6 \%$ & $89.8 \pm 4.8 \%$ & $89.2 \pm 3.3 \%$ & $87.8 \pm 2.3 \%$ & $90.2 \pm 4.5 \%$ \\
\hline & Right & $91.3 \pm 3.3 \%$ & $90.9 \pm 3.1 \%$ & $91.6 \pm 2.1 \%$ & $88.5 \pm 2.5 \%$ & $88.3 \pm 3.1 \%$ & $88.0 \pm 4.9 \%$ \\
\hline \multirow[t]{2}{*}{ VPAF } & Left & $88.6 \pm 3.1 \%$ & $90.4 \pm 3.7 \%$ & $88.9 \pm 3.1 \%$ & $91.6 \pm 1.9 \%$ & $89.8 \pm 1.9 \%$ & $90.3 \pm 2.5 \%$ \\
\hline & Right & $90.1 \pm 2.7 \%$ & $88.7 \pm 4.1 \%$ & $89.8 \pm 3.6 \%$ & $90.9 \pm 3.6 \%$ & $90.1 \pm 2.5 \%$ & $88.8 \pm 2.9 \%$ \\
\hline \multirow[t]{2}{*}{ AES } & Left & $91.5 \pm 2.3 \%$ & $89.7 \pm 3.1 \%$ & $90.5 \pm 1.9 \%$ & $11.7 \pm 3.7 \%$ & $10.3 \pm 4.3 \%$ & $91.5 \pm 4.1 \%$ \\
\hline & Right & $90.3 \pm 3.6 \%$ & $91.4 \pm 2.5 \%$ & $13.3 \pm 2.8 \%$ & $92.2 \pm 2.8 \%$ & $9.1 \pm 4.7 \%$ & $91.1 \pm 3.5 \%$ \\
\hline \multirow[t]{2}{*}{ AII } & Left & $89.8 \pm 2.9 \%$ & $89.3 \pm 1.7 \%$ & $90.4 \pm 3.3 \%$ & $89.1 \pm 2.5 \%$ & $91.8 \pm 2.7 \%$ & $90.8 \pm 2.9 \%$ \\
\hline & Right & $91.2 \pm 1.9 \%$ & $87.9 \pm 2.5 \%$ & $88.8 \pm 2.1 \%$ & $90.9 \pm 3.3 \%$ & $91.5 \pm 3.5 \%$ & $89.4 \pm 3.5 \%$ \\
\hline \multirow[t]{2}{*}{ IN } & Left & $93.5 \pm 4.1 \%$ & $91.2 \pm 3.1 \%$ & $92.4 \pm 3.1 \%$ & $93.3 \pm 4.4 \%$ & $93.8 \pm 4.9 \%$ & $90.2 \pm 4.5 \%$ \\
\hline & Right & $93.2 \pm 3.5 \%$ & $93.0 \pm 3.3 \%$ & $90.5 \pm 2.9 \%$ & $93.6 \pm 2.9 \%$ & $91.8 \pm 4.7 \%$ & $89.5 \pm 4.7 \%$ \\
\hline \multirow[t]{2}{*}{$\mathrm{T}$ (and VAF) } & Left & $93.0 \pm 3.5 \%$ & $95.7 \pm 4.1 \%$ & $92.3 \pm 3.3 \%$ & $91.4 \pm 3.6 \%$ & $89.4 \pm 4.9 \%$ & $90.7 \pm 3.3 \%$ \\
\hline & Right & $92.0 \pm 3.9 \%$ & $93.3 \pm 3.9 \%$ & $93.5 \pm 2.6 \%$ & $92.9 \pm 4.1 \%$ & $90.9 \pm 3.9 \%$ & $92.1 \pm 2.9 \%$ \\
\hline \multirow[t]{2}{*}{$\mathrm{dPE}$ (and iPE) } & Left & $92.3 \pm 3.1 \%$ & $94.5 \pm 2.0 \%$ & $91.8 \pm 2.6 \%$ & $92.3 \pm 1.7 \%$ & $91.0 \pm 3.3 \%$ & $89.9 \pm 4.3 \%$ \\
\hline & Right & $93.5 \pm 2.9 \%$ & $94.9 \pm 1.8 \%$ & $93.9 \pm 3.1 \%$ & $90.9 \pm 3.3 \%$ & $90.8 \pm 4.5 \%$ & $92.2 \pm 4.7 \%$ \\
\hline \multirow[t]{2}{*}{ vPE } & Left & $92.1 \pm 2.5 \%$ & $93.1 \pm 1.9 \%$ & $89.3 \pm 3.6 \%$ & $91.2 \pm 3.7 \%$ & $92.2 \pm 4.4 \%$ & $93.4 \pm 4.1 \%$ \\
\hline & Right & $91.3 \pm 2.2 \%$ & $91.3 \pm 2.5 \%$ & $92.7 \pm 3.1 \%$ & $90.5 \pm 2.3 \%$ & $91.5 \pm 4.7 \%$ & $94.5 \pm 4.5 \%$ \\
\hline
\end{tabular}

Values are means \pm SE. Values in bold are statistically different $(P<0.01)$ from preimplant and warm values. 


\section{A controls}

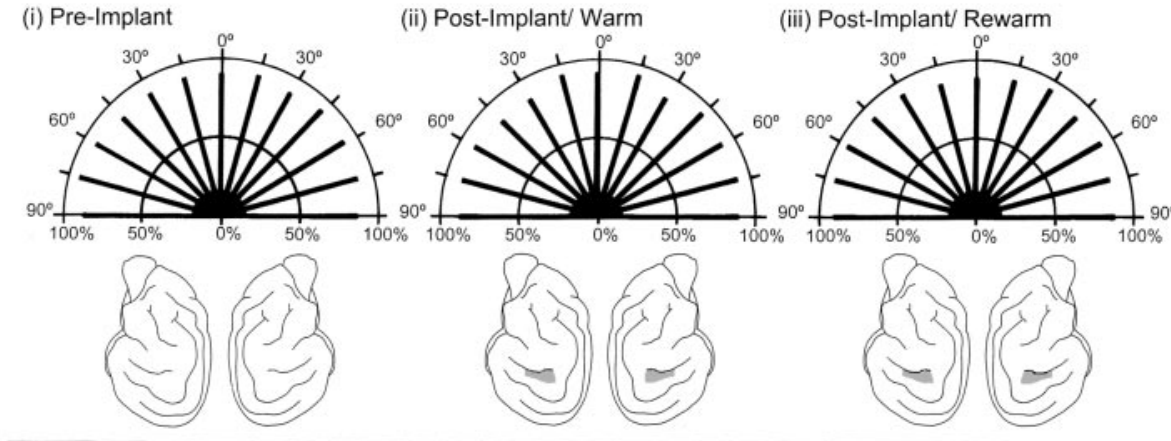

B Deactivations

(iv) Left

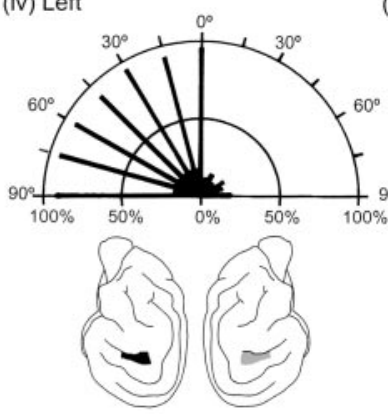

(v) Bilatera

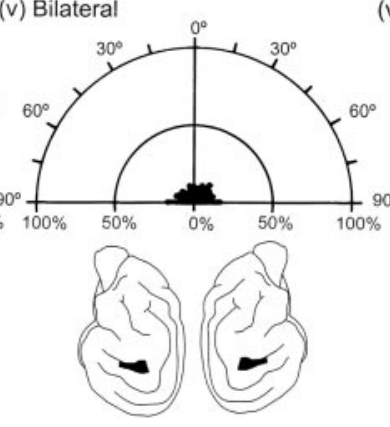

(vi) Right

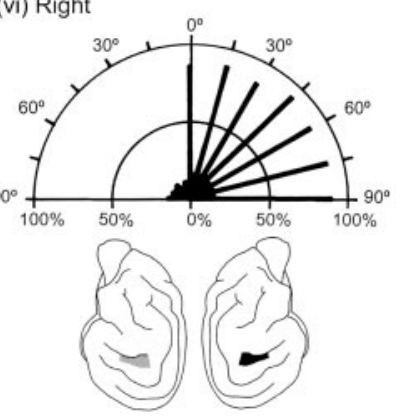

FIG. 5. Orienting responses to an acoustic stimulus during deactivation of PAF. For conventions, see Fig. 4. A: control data collected: $(i)$ before PAF cryoloop implantation, (ii) after PAF cryoloop implantation and before cooling in each testing session, and (iii) shortly after termination of cooling. $B$ : deactivation data collected: (iv) during cooling of left PAF, ( $v$ ) during bilateral cooling of PAF, and (vi) during cooling of right PAF. Note that unilateral deactivation of PAF caused sound localization deficits in the contralateral field with no impairments in the ipsilateral hemifield. Bilateral deactivation of PAF resulted in bilateral sound localization deficits. Data summarized from 7 animals.
$2.8 \%$ (Fig. $4 A i$ ) to $11.7 \pm 3.6 \%$ (Fig. 4Biv). In contrast, orienting responses into the left (ipsicooled) hemifield were maintained at normally high levels $(93.0 \pm 3.1 \%$ before cooling; $93.4 \pm 3.6 \%$ during cooling) and were unaffected by the cooling deactivation. The additional cooling of the right AI/DZ cryoloop resulted in a deficit throughout the left hemifield that was similar in magnitude to the deficit originally identified in the right hemifield (Fig. $4 B v$ ). In total, the bilateral deactivation of $\mathrm{AI} / \mathrm{DZ}$ resulted in an almost complete spatial localization impairment throughout the entire field examined, with performance significantly $(P<0.01)$ falling from $92.9 \pm$ $3.3 \%$ (Fig. 4 Aii) to $11.2 \pm 4.1 \%$ (Fig. $4 B v$ ). Therefore performance during bilateral deactivation of AI/DZ was not different from chance $(7.7 \%)$.

The termination of cooling the left AI/DZ cryoloop, although leaving the right $\mathrm{AI} / \mathrm{DZ}$ loop cooled, resulted in a restoration of normal orienting responses to acoustic stimuli presented in the right hemifield while continuing to leave performance in the left hemifield profoundly impaired (Fig. $4 B v i$ ). Compared with normal performance levels (Fig. 4Aii), unilateral deactivation of right AI/DZ significantly $(P<0.01)$ reduced orienting response accuracy in the left (contracooled) hemifield from $91.9 \pm 2.5$ to $10.2 \pm 3.1 \%$ (Fig. 4Bvi). Therefore unilateral deactivation of either the left (Fig. 4Biv) or right (Fig. 4Bvi) AI/DZ resulted in mirror-symmetric sound localization deficits (Table 2). Identical results were obtained when the order of cooling was reversed (right, bilateral, left) and when bilateral deactivation was performed without an intermediate unilateral deactivation step. Finally, during bilateral cooling deactivation when the animals did not accurately orient to the correct speaker, we identified that the animals tended to make responses to an incorrect speaker location in the correct hemifield. The errors made during cooling deacti- vation will be considered in greater detail in a later section of the RESULTS (see Orienting response accuracy).

Similar to the deficits identified during bilateral cooling of AI/DZ (Fig. 4Bv), bilateral cooling of PAF also resulted in almost complete spatial localization impairment throughout the entire field examined (Fig. 5Bv; Table 2). Furthermore, unilateral deactivation of either the left (Fig. 5Biv) or right (Fig. $5 B v i)$ PAF also resulted in mirror-symmetric sound localization deficits confined to the contralateral hemifield (Table 2). In contrast, bilateral deactivation of AAF did not result in any cooling-induced spatial localization errors to any positions throughout the $180^{\circ}$ field (Fig. 6Bv; Table 2). Moreover, deactivation of neither the right (Fig. 6Bvi) nor left (Fig. 6Biv) AAF resulted in any acoustic orienting deficits in either the contralateral or ipsilateral hemifields (Table 2). Similar to AAF, neither unilateral (Fig. 7) nor bilateral (Fig. 8) deactivation of VPAF yielded any acoustic spatial localization deficits (Table 2). The lack of any deficit during unilateral or bilateral deactivation of AAF or VPAF provides a strong contrast with the impressive deficits identified after unilateral and bilateral deactivation of AI/DZ (Fig. $4 B$ ) or PAF (Fig. 5B).

\section{Nontonotopically organized regions}

EXTENT OF DEACTIVATIONS. AES. Cooling of each of the AES loops deactivated the fundus and both the ventral and dorsal banks of the posterior two thirds of the AES (Fig. $3 E$ ). In the largest of the extents the deactivation spread slightly more dorsally onto the anterior ectosylvian gyrus and slightly more ventrally onto dorsal sylvian gyrus. Therefore cooling of each AES cryoloop silenced the acoustically responsive field of the AES (Clarey and Irvine 1986; Meredith and Clemo 1989; Mucke et al. 1982; Rauschecker and Korte 1993), the visually responsive field (AEV; Olson and Graybiel 1983, 1987), and 


\section{A controls}

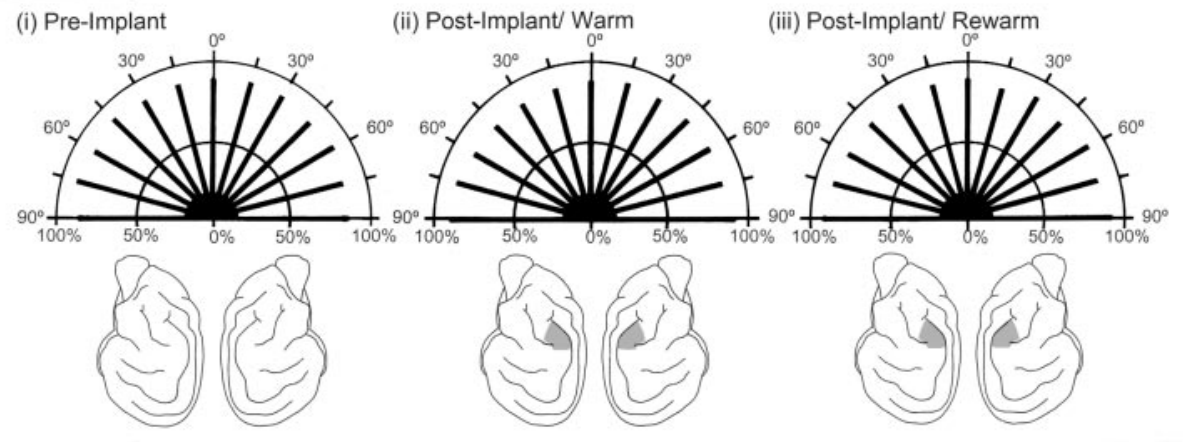

FIG. 6. Orienting responses to an acoustic stimulus during deactivation of AAF. For conventions, see Fig. 4. A: control data collected: (i) before AAF cryoloop implantation, (ii) after AAF cryoloop implantation and before cooling in each testing session, and (iii) shortly after termination of cooling. $B$ : deac-

\section{B Deactivations}

(iv) Left

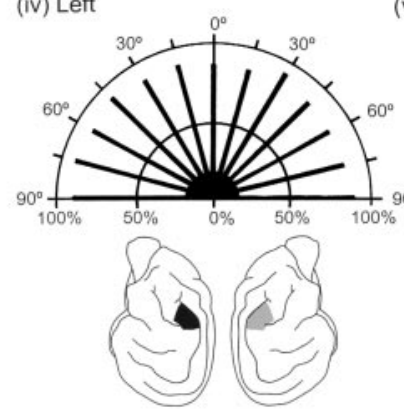

(v) Bilateral

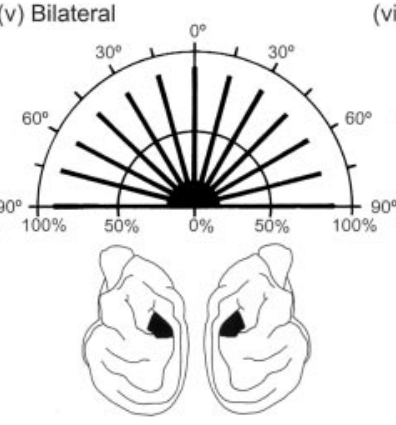

(vi) Right

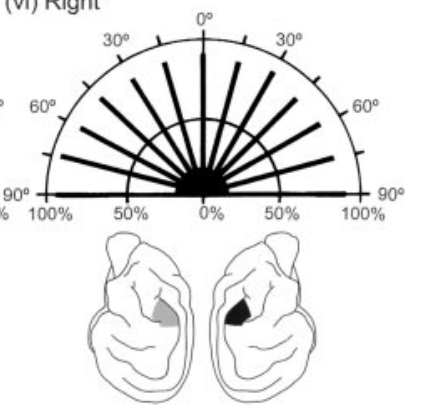
tivation data collected: (iv) during cooling of left AAF, $(v)$ during bilateral cooling of AAF, and $(v i)$ during cooling of right AAF. Note that neither unilateral nor bilateral deactivation of AAF resulted in sound localization deficits. Data summarized from 4 cats.

ventral portions of SIV (Mori et al. 1996). Even in the largest extents the deactivations did not spread ventrally into either AII or the anterior sylvian area (Fig. 3E; Clascá et al. 1997, 2000).

AII. Cooling of the AII cryoloops deactivated a band of cortex across the middle sylvian gyrus, ventral to AI, between the anterior and posterior ectosylvian sulci (Fig. 3F; Woolsey 1960). For the largest extents the deactivated region was about $8 \mathrm{~mm}$ long (anterior to posterior) and $6 \mathrm{~mm}$ wide (dorsal to ventral). For the smallest extents the deactivated region was about $8 \mathrm{~mm}$ long (anterior to posterior) and $4 \mathrm{~mm}$ wide (dorsal to ventral). In each case, the deactivation did not spread into either the anterior or posterior ectosylvian gyri. In the largest extents, the deactivation included the ventral-most portion of area AI. Therefore in all cases the deactivation included all of area AII as defined by Woolsey (1961) and Reale and Imig (1980).
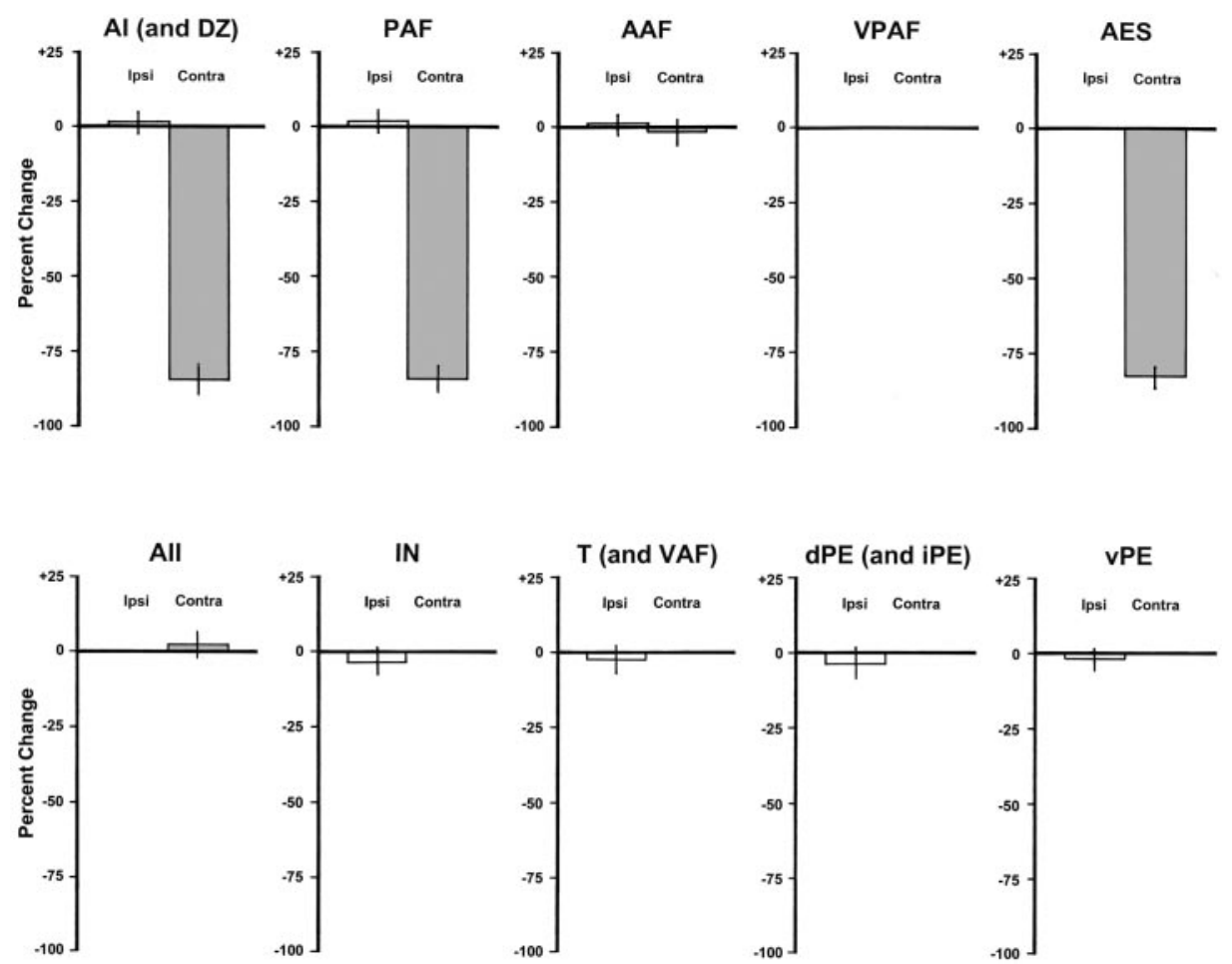
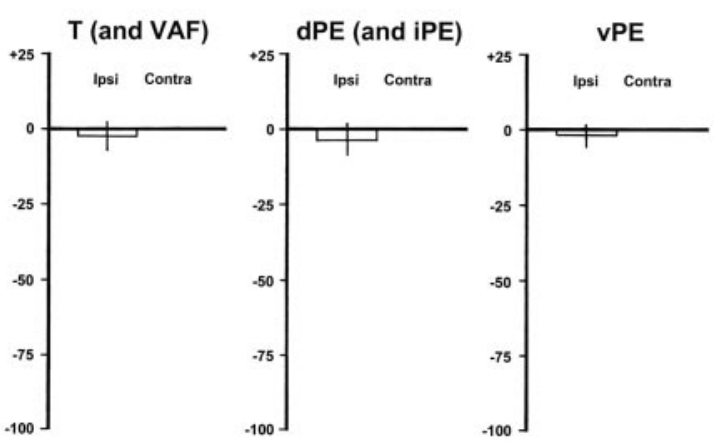

FIG. 7. Percentage change in acoustic localization, from control levels, during unilateral deactivation of each of the 10 cortical loci examined. Because of similarity in results, data for cooling the left and right loci are combined. Localization accuracy is shown for both the ipsilateral (open bars) and contralateral (shaded bars) hemifields. Percentage change $\leq 1 \%$ is not shown. Error bars indicate SE. Unilateral deactivations of $\mathrm{AI} / \mathrm{DZ}, \mathrm{PAF}$, or AES led to performance that was significantly reduced in the contralateral hemifield, with no change in performance in the ipsilateral hemifield. 

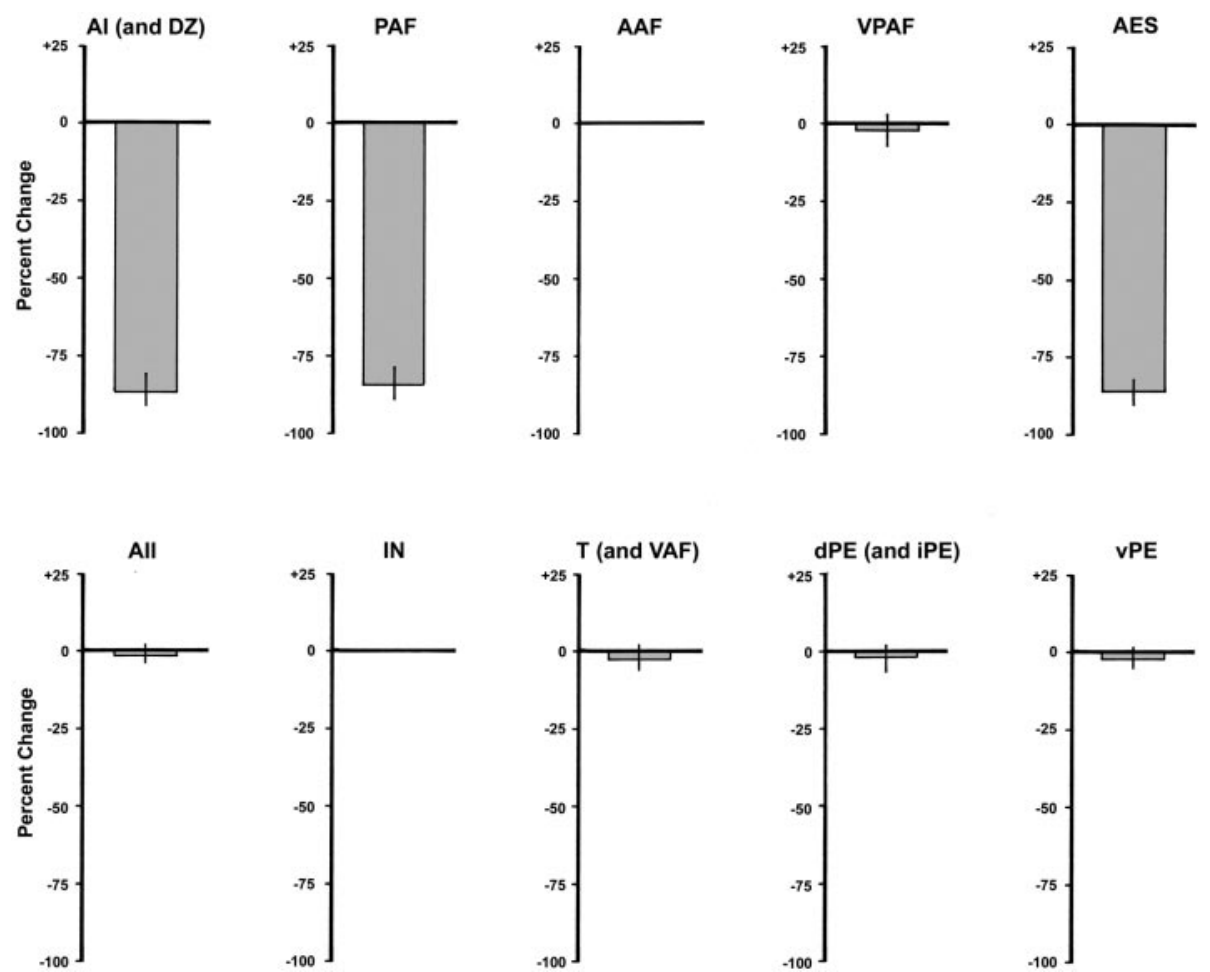

FIG. 8. Percentage change in acoustic localization, from control levels, during bilateral deactivation of each of the 10 cortical loci examined. Percentage change $<1 \%$ is not shown. Error bars indicate SE. Only bilateral deactivations of AI/ $\mathrm{DZ}, \mathrm{PAF}$, or AES led to performance that was significantly different from control levels.

IN. Cooling of the insular (IN) region loops deactivated a swath of cortex on the anterior sylvian gyrus, between the anterior ectosylvian and sylvian sulci (Fig. 3G). Each deactivation included portions of the lateral bank of the anterior ectosylvian sulcus and the anterior bank of the sylvian sulcus (Fig. 3G). Therefore the area IN loops deactivated the majority of the anterior sylvian area as defined by Clascá et al. (1997, 2000). The largest extents also deactivated the anterolateralmost aspect of AII and extended ventrally into the dorsal division of the agranular insular area as defined by Clascá et al. (1997, 2000).

Temporal (T) area (and VAF). Cooling of the cryoloops placed over the temporal (T) area deactivated a band of cortex across the posterior sylvian gyrus from the sylvian sulcus, anteriorly, to ectosylvian sulcus, posteriorly (Fig. $3 H$ ). In both the largest and smallest extents, this region of deactivation also included cortex on the posterior bank of the sylvian sulcus and cortex of the anterior bank of the ectosylvian sulcus (Fig. $3 H$ ). The largest of the extents also deactivated the posterolateralmost aspect of area AII, dorsally. The smallest deactivations did not extend beyond the ventral end of the PE sulcus. Therefore each of the temporal area loops deactivated both the temporal area (area Te of Clascá et al. (2000) and the ventral auditory field (VAF or V; Reale and Imig 1980).

Dorsal posterior ectosylvian (dPE) gyrus (and iPE). Cooling of the dPE loops deactivated a $5 \times 13-\mathrm{mm}$ region at the posterior bend of the ectosylvian gyrus that extended vertically down the crown of the PE gyrus (Fig. 3I). The region of deactivation extended from the middle suprasylvian sulcus, medially, to the middle of the PE sulcus, laterally (Fig. 3I). In none of the dPE/iPE cases did the deactivation enter the middle suprasylvian, posterior suprasylvian, or PE sulci. Therefore the deactivations included both the dorsal (dPE) and intermediate (iPE) divisions of the PE gyrus, or EPD and EPI, of Winer (1992).
Ventral posterior ectosylvian ( $v P E$ ) gyrus. Of the ten loci examined, the smallest amount of variability was in the size of the vPE deactivations. Cooling of the vPE loops deactivated a $4 \times 9-\mathrm{mm}$ region on the posterior half of the ventral PE gyrus (Fig. 3J). None of the deactivations extended into the PE sulcus, anteriorly (Fig. 3J). The largest deactivations did extend into the anterior bank of the PE sulcus, posteriorly. Therefore the deactivation included the ventral division of the PE gyrus (vPE), or EPV, of Winer (1992) and portions of area PS of Updyke (1986).

BEHAVIOR. Controls. Data collected before AES cooling loop implantation show that the cats were able to accurately orient to acoustic stimuli presented out to $90^{\circ}$ in either the left or right hemifields (Fig. 9Ai). After implantation of the cryoloops within AES there was no change in orienting performance (Fig. 9Aii; Table 2). Finally, after the termination of cooling deactivation, orienting responses to acoustic stimuli returned to normal levels (Fig. 9Aiii; Table 2). Therefore orienting responses were consistent among the three control conditions and were not different from the control results obtained from the four tonotopically organized regions. Finally, virtually identical control results were obtained from the other five nontonotopically organized regions of acoustically responsive cortex (Table 2).

Deactivations. Data collected during bilateral and unilateral deactivation of the AES in four cats (Table 1) are summarized in Fig. 9. Overall, orienting responses during both bilateral and unilateral cooling of the AES were very similar to orienting responses during cooling of either AI/DZ (Fig. 4B) or PAF (Fig. 5B). Unilateral cooling of the left AES significantly $(P<$ 0.01 ) reduced orienting response accuracy into the right (contracooled) hemifield from $91.4 \pm 2.5 \%$ (Fig. 9Aii) to $13.3 \pm$ $2.8 \%$ (Fig. 9Biv) while leaving responses into the left (ipsicooled) hemifield unchanged $(89.7 \pm 3.1 \%$ before cooling; 
A Controls

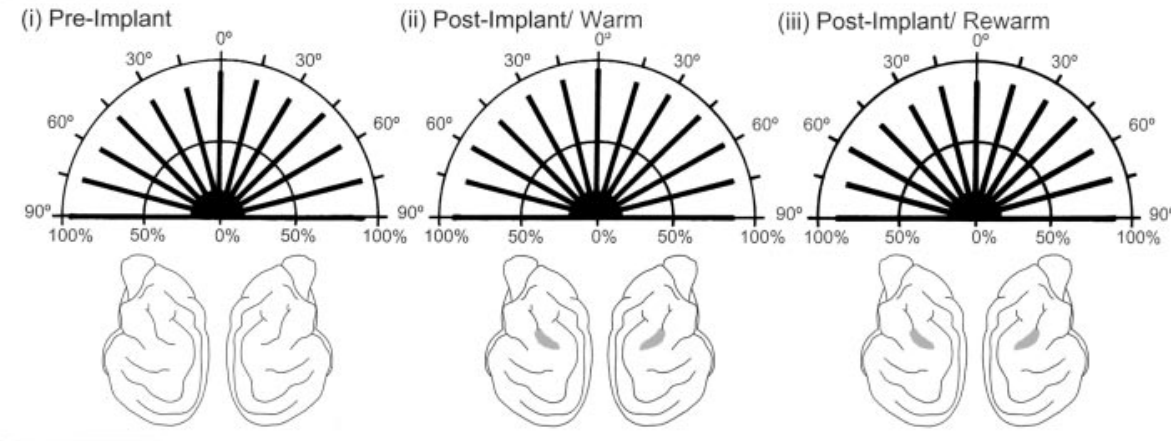

B Deactivations

(iv) Left

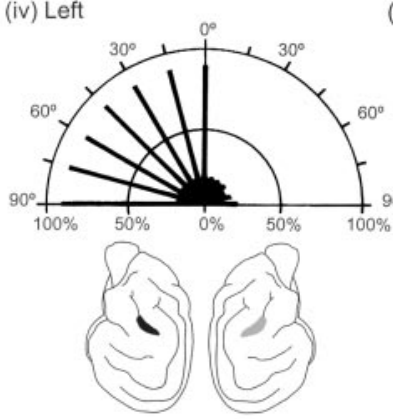

(v) Bilateral

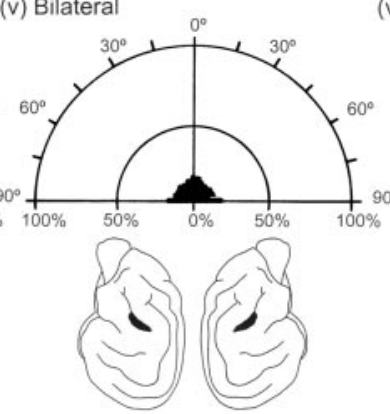

(vi) Right

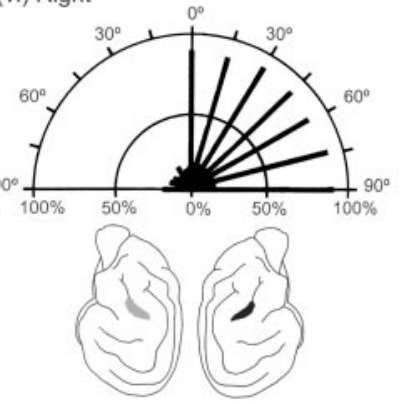

FIG. 9. Orienting responses to an acoustic stimulus during deactivation of AES. A: control data collected: (i) before AES cryoloop implantation, (ii) after AES cryoloop implantation and before cooling in each testing session, and (iii) shortly after termination of cooling. $B$ : deactivation data collected: (iv) during cooling of left AES, ( $v)$ during bilateral cooling of AES, and (vi) during cooling of right AES. Note that unilateral deactivation of AES caused sound localization deficits in the contralateral field with no ipsilateral impairment. Bilateral deactivation of AES resulted in bilateral deficits. For conventions, see Fig. 4. Data summarized from 4 cats.
$90.5 \pm 1.9 \%$ during cooling). The additional cooling of the right AES cryoloop resulted in an additional deficit throughout the left hemifield that was nearly identical in magnitude to the deficit originally shown in the right hemifield (Fig. 9Bv). Therefore bilateral deactivation of the AES resulted in an almost complete spatial localization impairment through the entire field, with performance falling significantly $(P<0.01)$ from $92.6 \pm 2.1 \%$ (Fig. 9Aii) to $9.7 \pm 4.1 \%$ (Fig. $9 B v$ ), and was not different from chance performance $(7.7 \%)$. Therefore the bilateral deficit (Fig. 9Bv) was similar to that identified during bilateral cooling of either AI/DZ (Fig. $4 B v$ ) or PAF (Fig. $5 B v$ ). After the termination of cooling the left AES, while leaving the right AES cooled, orienting into the left hemifield remained at significantly $(P<0.01)$ reduced levels $(11.7 \pm$ $3.7 \%$; Fig. 9Bvi), whereas orienting into the right hemifield returned to normal levels $(92.2 \pm 2.8 \%$; Fig. $9 \mathrm{Bvi})$. Therefore similar to the deficits identified during cooling of either AI/DZ (Fig. 4B) or PAF (Fig. 5B), unilateral deactivation of either the left (Fig. 9Biv) or right (Fig. 9Bvi) AES resulted in mirrorsymmetric sound localization deficits (Table 2).

In contrast, bilateral deactivation of none of the other nontonotopically organized regions of acoustically responsive cortex resulted in any cooling-induced spatial localization errors to any positions throughout the $180^{\circ}$ field examined (Fig. 8; Table 2). Moreover, unilateral deactivation of neither the right nor left loci of AII, IN, T/VAF, $\mathrm{dPE} / \mathrm{iPE}$, or vPE resulted in any acoustic orienting deficits in either the contralateral or ipsilateral hemifields (Fig. 7; Table 2). In total, the only nontonotopically organized region of auditory cortex that, when deactivated, yielded sound localization deficits was AES (Table 2). Therefore two of the four tonotopically organized regions and one nontonotopic region are critical for accurate sound localization. These results show that tonotopy is not a prerequisite for an area to be involved in sound localization.
Overall, the results show that tonotopy is doubly dissociated from localization: localization deficits were observed in tonotopic and nontonotopic fields and tonotopic fields did or did not show localization deficits during cooling.

\section{Hemispheric specialization}

Each of the ten loci studied was examined in at least three cats (Table 1). This experimental configuration permitted us to test for any possible hemispheric asymmetries in cooling impact and determine whether there was any evidence for lateralization of function for this behavior in the cat. In no condition (brain region or state of cooling) did the left or right hemispheres differ significantly (Table 2). For example, cooling of left $\mathrm{AI} / \mathrm{DZ}$ resulted in a significant $(P<0.01)$ reduction in accurate orienting responses in the contralateral field from $92.3 \pm 2.8$ to $11.7 \pm 3.6 \%$ (compare Fig. 4, Aii and Biv). Similarly, deactivation of right AI/DZ resulted in a significant $(P<0.01)$ reduction in accurate orienting responses in the contralateral field from $91.9 \pm 2.5$ to $10.2 \pm 3.1 \%$ (compare Fig. 4, Aii and Bvi). This null result permitted us to combine blocks of trials obtained during unilateral cooling of the right or left hemispheres. Similar null results were identified when performance during left and right hemisphere deactivations were compared for each of the nine other cortical loci examined. Therefore in Fig. 7 we plot in percentage correct by ipsilateral and contralateral (averaged over left and right) hemifields after unilateral deactivations.

\section{Orienting response accuracy}

During bilateral or unilateral cooling deactivation of areas $\mathrm{AI} / \mathrm{DZ}, \mathrm{PAF}$, or AES, there was a profound reduction in orienting response accuracy to an acoustic stimulus. Before 
A Al/DZ

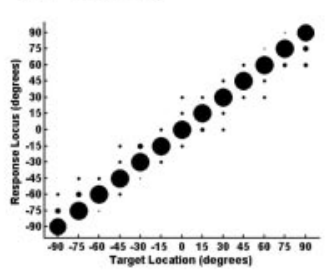

B PAF
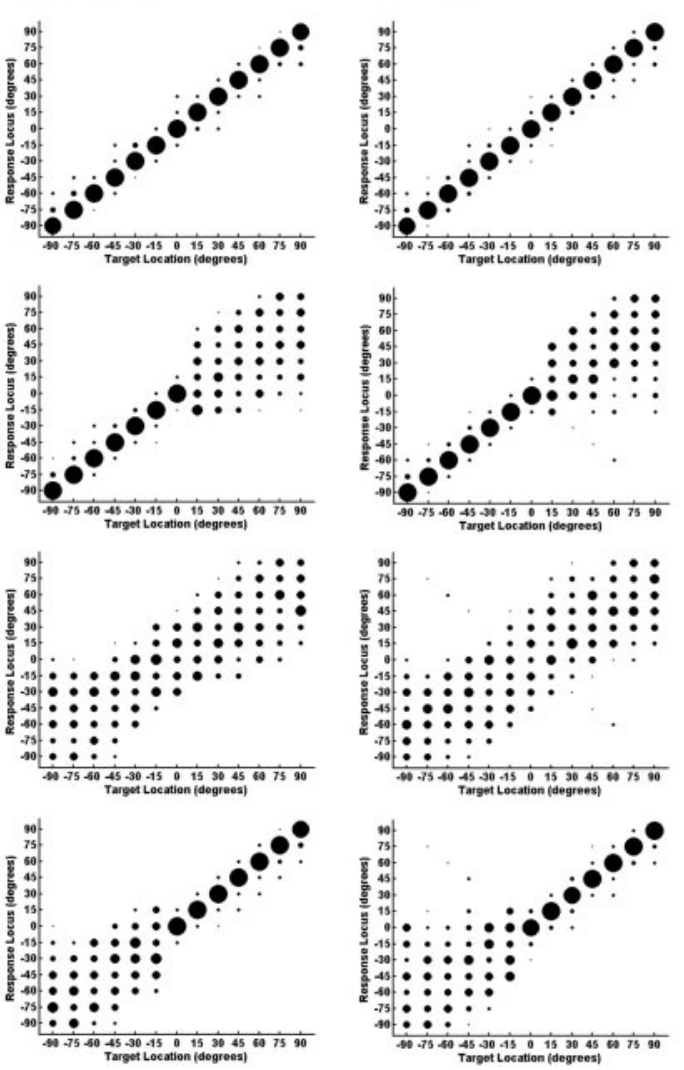

cooling deactivation, the animals had previously been trained to report to the central $\left(0^{\circ}\right)$ position when they were unable to detect and localize the sound source. However, during cooling deactivation, when the animals did not respond to the correct sound location, they seldom went to the central position. Instead, we found that the animals made responses to incorrect speaker locations. Plots of the animals' accuracy before cooling deactivation and during left, bilateral, and right deactivation of each of these three loci are provided in Fig. 10. In general, responses to the target location were highly accurate before cooling deactivation (Fig. 10i). For both hemifields, these responses ranged between 82 and $93 \%$ accurate. However, during unilateral cooling deactivation of the left hemisphere (Fig. 10ii), accuracy dropped to between 14 and 24\% throughout the contralateral hemifield. For areas AI/DZ, PAF, and AES, inaccurate responses tended to stay within the same hemifield as the target location and were composed of both undershoots and overshoots of the target position with the majority of the errors being undershoots (Fig. 10ii, contralateral field). During cooling of left AI/DZ, PAF, or AES the percentage of errors made into the same hemifield as the target stimulus were 91.8, 95.4, and 92.8\%, respectively. Similarly, unilateral cooling deactivation of the right hemisphere (Fig. $10 i v)$ also resulted in a profound reduction in orienting accuracy throughout the contralateral field. The types of errors made during right hemisphere deactivations paralleled those identified during left hemisphere deactivation. For example, with respect to cooling of right $\mathrm{AI} / \mathrm{DZ}, \mathrm{PAF}$, or $\mathrm{AES}$ the percentage of errors made into the same hemifield as the target stimulus were $97.7,95.8$, and $93.3 \%$, respectively.
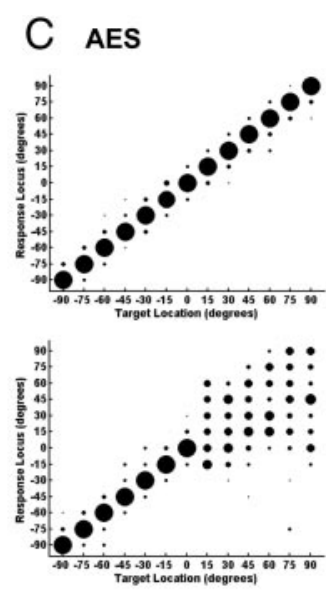

FIG. 10. Spatial localization accuracy to the acoustic target during unilateral or bilateral deactivation of AI/DZ, PAF, or AES. Target position is indicated on the $x$-axis (negative values indicate left hemifield); orienting response is indicated on the $y$-axis. Area of the circle at each position indicates the percentage of correct responses. $i$ : accuracy before and after any cooling deactivations. $i i$ : accuracy during left cooling deactivation. Note errors in right hemifield. iii: accuracy during bilateral deactivation. Note errors throughout the tested field. $i v$ : accuracy during right cooling deactivation. Note errors in left hemifield.

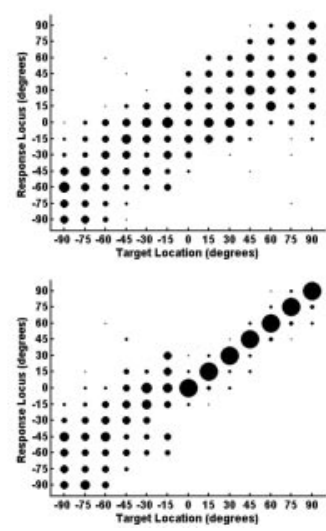

Bilateral deactivation of AI/DZ, PAF, or AES yielded profound sound localization errors across the entire field (Fig. 10iii). The errors identified during bilateral deactivation of each of the three areas were comparable. Overall, the errors made to more peripheral locations tended to be of greater magnitude, with the range of errors being greatest at the most lateral locations tested. Moreover, even during bilateral deactivation, errors tended to be made to the same hemifield as the target location. For example, during bilateral cooling of AI/DZ, PAF, or AES the percentage of errors made into the same hemifield as the target stimulus were $94.3,95.2$, and $93.2 \%$, respectively. Therefore during bilateral deactivation of AI/DZ, PAF, or AES, although the cats selected the target location at chance levels only, they generally identified the correct hemifield.

\section{Orienting to visual stimuli}

To confirm that the acoustic spatial localization errors we identified during cooling of AI/DZ, PAF, and AES were unique to one modality and not general motor deficits, we also examined the ability of the cats to orient to a visual stimulus introduced at the exact same spatial locations examined with the acoustic stimuli. In this paradigm, the testing procedures were identical with the only difference being that the $100-\mathrm{ms}$ broad-band acoustic stimulus (target stimulus) was replaced with a flashed red 2-V (DC) LED. During unilateral or bilateral cooling deactivation of AI/DZ, PAF, or AES, no significant changes in orienting to visual targets were identified anywhere in the visual field. Therefore the acoustic spatial localization deficits identified during unilateral and bilateral deactivation of 


\section{A Controls}

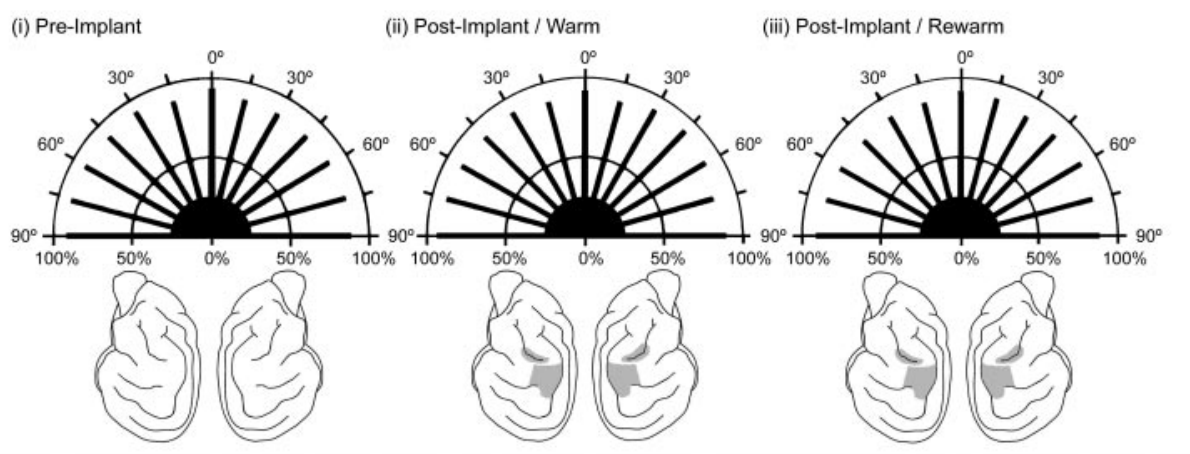

B Deactivations (iv) Left AES $\quad$ (v) Left AES and Right AI/DZ

(v) Left AES and Right AI/DZ
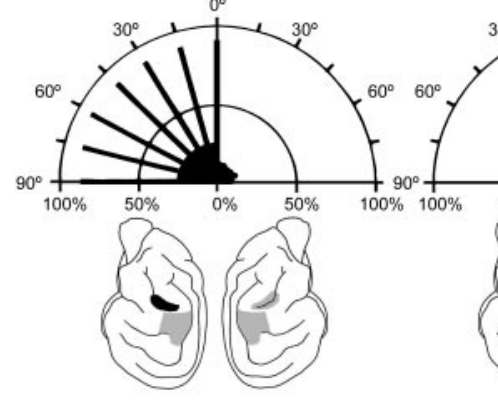

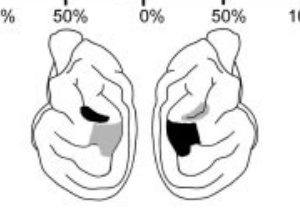

AI/DZ, PAF, or AES were specific acoustic impairments without accompanying visual or motor deficits.

\section{Heterotopic deactivations}

The primary purpose of the present investigation was to examine sound localization behavior during bilateral deactivations of specific regions throughout the acoustically responsive cerebrum. During this investigation, we primarily focused our bilateral deactivations on cooling homotopic loci (i.e., left $\mathrm{AI} / \mathrm{DZ}$ and right $\mathrm{AI} / \mathrm{DZ}$ ). In addition to these investigations, we also examined the consequences of bilateral heterotopic deactivations. After we had determined the three cortical loci that specifically contribute to sound localization, we also investigated the outcome of three specific heterotopic deactivations (AES-AI/DZ, AES-PAF, and PAF-AI/DZ).

As shown earlier, unilateral deactivation of AES in the left hemisphere (Figs. 9Biv and 11Biv) or unilateral deactivation of $\mathrm{AI} / \mathrm{DZ}$ in the right hemisphere (Figs. $4 B v i$ and $11 B v i$ ) each resulted in profound sound localization deficits in the contralateral field. When both of these heterotopic sites were deactivated simultaneously, there was a substantial decrease in accurate sound localization across the entire field (Fig. 11Bv). Therefore heterotopic deactivation of AES and AI/DZ resulted in an almost complete spatial localization impairment through the entire field, with performance falling from levels of $93.5 \pm$ $2.8 \%$ (Fig. 11Aii) before deactivation to levels of $9.1 \pm 3.1 \%$ (Fig. $11 B v$ ) after deactivation. These impaired levels of performance were not different from chance $(7.7 \%)$. The magnitude of the decrease was comparable to the bilateral deficits we had previously identified during bilateral homotopic cooling of either AES (Fig. 9Bv) or AI/DZ (Fig. 4Bv). Therefore the additive deficit identified when two unilateral deactivations from heterotopic sites are combined (AES-AI/DZ) is similar to

FIG. 11. Orienting responses to an acoustic stimulus during heterotopic deactivations in AES and AI/DZ. For conventions, see Fig. 4. $A$ : control data collected: $(i)$ before cryoloop implantation, (ii) after cryoloop implantation and before cooling in each testing session, and (iii) shortly after termination of cooling. $B$ : deactivation data collected: (iv) during cooling of left AES, $(v)$ during cooling of left AES and right $\mathrm{AI} / \mathrm{DZ}$, and (vi) during cooling of right AI/DZ. Note that heterotopic deactivation of AES and AI/DZ yielded results similar to homotopic deactivation of AES (Fig. 9Bv) or AI/DZ (Fig. 4Bv). Data from cat 8 (Table 1).

\section{I S C U S S I O N}

\section{Summary}

In this study we divided the expanse of acoustically responsive cortex into ten regions and examined the contributions of each of these regions to sound localization during both unilateral and bilateral cooling deactivation. Overall, one major conclusion that can be drawn from the present results is that most of auditory cortex is not necessary for sound localization as assessed in this study. We identified three regions of auditory cortex that are critical for accurate sound localization. These three regions are primary auditory cortex and the dorsal zone (AI/DZ), the posterior auditory field (PAF), and the auditory field of the anterior ectosylvian sulcus (AES). The fact that deactivation of any one region (AI/DZ, PAF, or AES) is sufficient to produce a deficit indicates that normal function of all three regions is necessary for normal sound localization. For each of these three regions, unilateral deactivation resulted in profound sound localization deficits confined to the hemifield contralateral to the deactivation. Bilateral deactivation of each of the three regions, or any bilateral combination thereof, 
resulted in sound localization deficits throughout the entire field. Furthermore, these localization deficits were uniquely acoustic because there were no localization deficits identified during either unilateral or bilateral deactivation of any of these sites when a visual stimulus was used.

An additional interesting point that is made possible only in a report that examines the consequences of both bilateral and unilateral deactivations is the result from the zero degree position. Unilateral cooling conditions (either left or right hemispheres) result in a contralateral deficit that spares the midline (zero degree position; Figs. 4, 5, and 9). However, during bilateral cooling, localization at the midline position is impaired. Therefore neither hemisphere is necessary for accurate localization at the midline because either hemisphere is sufficient.

\section{Sound localization deficits versus deafness}

During bilateral deactivation of AI/DZ, PAF, or AES, severe sound localization deficits were identified throughout the $180^{\circ}$ field examined. These deficits were so severe that accuracy to any given target fell to chance levels. This result begs the question as to whether the animals had profound spatial localization deficits during bilateral deactivation or whether the animals were actually deaf. There are two observations from this study that confirm that the deficits are of sound localization and not of deafness. First, irrespective of whether the animals accurately localized the stimulus, they initiated a response after the onset of the acoustic stimulus. Therefore the animals could clearly hear the stimulus, but not accurately localize it. Second, an examination of the errors made during bilateral deactivation of AI/DZ, PAF, and AES (Fig. 10) reveals that the vast majority of errors were made to positions in the same hemifield as the target locus. Thus although the animals were unable to accurately report the location of the stimulus within a hemifield, they were able to accurately report the hemifield in which the acoustic stimulus was presented. This result is in agreement with previous studies that examined the ability of cats to discriminate an acoustic stimulus presented in the left or right hemifield after bilateral destruction of AI (Strominger 1969a). In summary, our findings, and the work of others, demonstrate that the deficits identified during bilateral cooling deactivation of $\mathrm{AI} / \mathrm{DZ}, \mathrm{PAF}$, or AES are related to sound localization and not deafness.

Our results using reversible cooling to deactivate regions of auditory cortex demonstrated that deafness did not result as a consequence of the deactivations. Our findings are in agreement with numerous other studies that did not find evidence of total deafness after physical lesions of auditory cortex (see review of Heffner 2005). Additionally, it was previously identified that ablations of auditory cortex do not eliminate the ability to discriminate the intensity of an acoustic stimulus (Neff et al. 1975). Deactivation of auditory cortex, whether temporary or permanent, has been found to yield other acoustic deficits in addition to those of sound localization. Deactivation of primary auditory cortex results in a wide range of acoustic deficits, including: increases frequency discrimination thresholds (Harrington et al. 2001; Heffner and Masterton 1978; Massopust et al. 1970), disrupts the ability to perceive the pitch of complex tones (Whitfield 1980), interferes with the ability to identify changes in frequency (Harrington et al. 2001; Kelly and Whitfield 1971), and disrupts the ability to discriminate vocalizations (Heffner and Heffner 1986) or speech (Dewson et al. 1969). In the future, it would be interesting to examine the nonspatial deficits that might arise from deactivating other nonprimary regions of auditory cortex.

\section{Task-specific sound localization deficits after bilateral deactivations of auditory cortex}

The vast majority of previous behavioral studies investigated sound localization in animals after unilateral or bilateral ablation of primary auditory cortex alone, or primary auditory cortex combined with many nonprimary areas. Although the regions of cortex investigated have remained fairly constant across species, the types of behavioral testing techniques have varied widely. These tasks are different from one another in terms of both the behavioral response and the number of sound sources and their locations within the hemifields. With respect to behavioral response, several different classes of tasks have been used: 1) left versus right discriminations; 2) orienting tasks (which include body orienting, head orienting, and eye movements); 3) unconditioned orienting tasks; and 4) conditioned-avoidance tasks.

LEFT VERSUS RIGHT DISCRIMINATIONS. Regardless of the position of the sound source within a hemifield, many studies have had animals indicate whether a sound source was located in the left or right hemifield. For carnivores, both cats and ferrets, studies that required the animals to discriminate sounds between the left and right hemifields found profound deficits after large ablations of all auditory cortices (Kavanagh and Kelly 1987; Neff et al. 1956; Strominger 1969b). In contrast, the animals had little difficulty distinguishing sounds presented in the left versus right hemifield after ablations of just primary auditory cortex (Kavanagh and Kelly 1987). Furthermore, when animals had to distinguish sounds within the left or right hemifield, profound sound localization deficits were evident when primary auditory cortex was destroyed (Kavanagh and Kelly 1987). Our present results are in agreement with both of these observations (see Fig. 10iii). Overall, bilateral deactivation of primary auditory cortex severely impairs the ability to discriminate the spatial location of sounds within a hemifield, but not the spatial location of sounds between the left and right hemifields.

ORIENTING TASKS. In sound localization tasks, a popular reporting mechanism has been to use orienting of the head or whole body toward the stimulus, which is then often accompanied with an approach to the sound source (Heffner and Heffner 1990; Jenkins and Masterton 1982; Kavanagh and Kelly 1987; Malhotra et al. 2004; Neff et al. 1956; Rauschecker and Kniepert 1994). Consistent in these studies of carnivores and monkeys are the findings that unilateral deactivations of auditory cortex impair sound localization within the hemifield contralateral to the deactivated cortex and that bilateral ablation of auditory cortex impairs sound localization throughout the entire field. We have been unable to identify any studies that have compared sound localization using head orienting versus whole body orienting during deactivations of auditory cortex.

The study of Jenkins and Merzenich (1984) also examined sound localization using an orienting task. With the exception 
of one case (C0140), nearly all the cats examined by Jenkins and Merzenich (1984) were in agreement with the results reported in the present study. In case C0140 most of auditory cortex was destroyed except for one vertical band through the primary auditory cortex. The unilateral cortical lesion appears to have included area PAF, but not AES. Jenkins and Merzenich (1984) reported that the cat was impaired at localizing any frequencies in the contralesional hemifield that were not preserved in the spared region of primary auditory cortex. However, the results from the present study suggest that the lesion of PAF alone should have impaired contralesional sound localization, even at the frequencies spared in AI. Because the cat was not tested for a minimum of 3 weeks after the lesion, we suggest that the lack of impairment was the result of a recovery of function after the lesion of PAF. This recovery of function is not identified during reversible deactivation of PAF (present study).

UNCONDITIONED ORIENTING TASKS. Both the left versus right discrimination tasks and orienting tasks required conditioned responses. However, it is also possible to study unconditioned responses to a sound source locus. For example, cats will reflexively orient their heads to a white-noise sound burst. Beitel and Kaas (1993) examined unconditioned head orienting responses to white-noise bursts after both unilateral and bilateral ablations of auditory cortex in its entirety. Beitel and Kaas (1993) found that bilateral removal of auditory cortex severely impaired the ability of cats to accurately orient to a sound source. However, in cats with unilateral ablations of auditory cortex, there were no deficits in orienting to sounds presented in either the contralateral or ipsilateral hemifields (Beitel and Kaas 1993). This result is contrary to the results using conditioned orienting tasks that found that unilateral destruction of all acoustically responsive cortex resulted in sound localization impairments in the contralateral, but not ipsilateral, hemifield (Casseday and Diamond 1977; Neff 1968; Neff et al. 1956; Strominger 1969b; Thompson and Welker 1963; Whitfield et al. 1972). Therefore although the conditioned and unconditioned orienting deficits are consistent for bilateral ablations of auditory cortex, profound conditioned orienting deficits follow unilateral ablations of auditory cortex, whereas no unconditioned orienting deficits follow similar unilateral ablations.

With respect to the present study, the study of Beitel and Kaas (1993) differs not only in the behavioral measures used, but also in the deactivation methods used. In the study of Beitel and Kaas (1993) deficit attenuation after the unilateral lesions may be a possible explanation for the lack of a sound localization deficit. The cats may have actually had a deficit immediately after the lesion. Unfortunately, it is likely that the cats were first tested weeks after the lesion and after the deficits may have attenuated as the result of cortical plasticity. One of the great advantages of using reversible deactivation approaches is that the confound of cortical plasticity can be largely avoided (Lomber 1999).

CONDITIONED-AVOIDANCE TASKS. Conditioned-avoidance tasks are also used to examine sound localization after ablations of auditory cortex. In these tasks animals are typically trained to make or break contact with a water spout to indicate the location of a sound source. The animal learns to break contact with the water spout because it will receive a mild electric shock if it fails to do so. Using this procedure an animal can be trained to perform a two-choice discrimination, such as a left-right discrimination or the discrimination of two positions within the same hemifield. The use of these conditionedavoidance procedures with monkeys confirms the left versus right discrimination results described earlier for cats and ferrets. Specifically, bilateral deactivation of primary auditory cortex severely impairs the ability of monkeys to discriminate the spatial location of sounds within a hemifield, but not the spatial location of sounds between the left and right hemifields (Heffner 1997; Heffner and Heffner 1990).

\section{Comparisons with other species}

In the present study, both unilateral and bilateral deactivation of AI/DZ, PAF, or AES yielded profound sound localization deficits. In this section, these results will be considered with data from homologous areas in other species.

PRIMARY AUDITORY CORTEX (AI). With respect to individual regions of auditory cortex, nearly all behavioral studies of sound localization examined the role of primary auditory cortex, regardless of species. The results from these studies are very consistent. In all mammals with highly developed cerebral cortices, unilateral ablations or deactivations restricted to primary auditory cortex result in spatial localization deficits restricted to the contralateral field. Furthermore, bilateral deactivation of primary auditory cortex results in sound localization deficits throughout the auditory field. These deficits after AI deactivations have been identified in cats (Jenkins and Masterton 1982; Jenkins and Merzenich 1984; Malhotra et al. 2004), ferrets (Kavanagh and Kelly 1987; Smith et al. 2004), and monkeys (Heffner and Masterton 1975; Wegener 1964). The results from the present study are in agreement with these earlier studies. However, similar results were not obtained in rats. Bilateral destruction of primary auditory cortex in the rat does not result in spatial localization errors (Kelly 1980; Kelly and Glazier 1978; Kelly and Kavanagh 1986). Furthermore, when these ablations are expanded to include all regions of acoustically responsive cortex, no significant sound localization deficits can be identified (Kelly 1980; Kelly and Glazier 1978; Kelly and Kavanagh 1986). These results contrast with those identified in carnivores (cats and ferrets) and primates (old- and new-world monkeys).

A plausible explanation for the lack of any spatial localization errors after bilateral destruction of primary auditory cortex in the rat is that rats do not localize sounds well within the lateral fields. Kavanagh and Kelly (1986) reported that normal rats are virtually incapable of lateral field sound localization of brief sounds and base their responses primarily on left versus right field differences. Therefore because we argue that the sound localization deficits in cats are primarily within field deficits (rather than left vs. right), the results obtained from rats may not be in such sharp contrast to those for other species.

POSTERIOR AUDITORY FIELD (PAF). In nearly all mammals, electrophysiological investigations have identified a field posterior, or posterior and ventral, to primary auditory cortex that contains a tonotopic organization. A posterior field was previously identified in the cat (Imig et al. 1982; Phillips and Orman 1984), ferret (Bizley et al. 2005), rat (Doron et al. 2002; Horikawa et al. 1988; Sally and Kelly 1988), long-eared hedgehog (Hemiechinus auritus) (Batzri-Izraeli et al. 1990), 
and Mongolian gerbil (Thomas et al. 1993). A caudomedial field was identified in the monkey (Merzenich and Brugge 1973; Morel et al. 1993; Rauschecker et al. 1997), but its topographic axis is reversed with regard to those of the other species. Therefore homologies between auditory areas in the monkey and any other species remain unclear.

In the cat, neurons in PAF appear to perform many functions that would be expected of neurons that process information relevant to sound localization. For example, neurons in PAF have increased spatial sensitivity (Stecker et al. 2003), a more uniform distribution of preferred locations (Stecker et al. 2003), greater tolerance to changes in stimulus intensity (Heil and Irvine 1998; Loftus and Sutter 2001; Phillips et al. 1995), and their latencies vary strongly with stimulus location (Stecker et al. 2003). Given these neuronal attributes, it was not surprising that unilateral or bilateral deactivation of PAF resulted in profound spatial localization deficits (present study). Unfortunately, at a behavioral level, no known deactivation studies have been conducted on the posterior field in any other animal. However, based on tonotopic organization and neuronal response properties, we propose that the posterior suprasylvian field (PSF) of the ferret (Bizley et al. 2005) is homologous to cat PAF.

ANTERIOR ECTOSYLVIAN SULCUS (AES). In the cat, AES contains adjacent sensory fields, with some overlap, that are responsive to visual (Olson and Graybiel 1987), auditory (Clarey and Irvine 1986; Rauschecker and Korte 1993), or somatosensory (Clemo and Stein 1982) stimuli (Rauschecker 1995). Despite the multiple sensory representations present in AES, deactivation of all three representations produces acoustic, but not visual, localization errors (Lomber and Payne 2004; Malhotra et al. 2004; present study). AES is also the major source of auditory cortical input to the superior colliculus (Harting et al. 1992; Meredith and Clemo 1989; Tortelly et al. 1980). The superior colliculus (SC) plays a key role in orienting of the head and eyes to acoustic stimuli (Apter 1946; Hess et al. 1946; Lomber et al. 2001) and the deeper layers of the SC contain a map of auditory space (Middlebrooks and Knudsen 1984; Palmer and King 1982).

Although it is unclear whether a cortical region similar to cat AES can be found in the monkey, there is evidence from ferrets that a region similar to AES may exist. In the ferret, cortex of the pseudosylvian sulcus (PSS) may be homologous to cat AES (Bizley et al. 2005; Manger et al. 2005).

\section{A C K N O W L E D G M EN T S}

We thank A. Hall for assistance in testing many of the animals examined in this study and for assistance in preparing the figures. We thank S. Bolinger, A. Moszkowicz, L. Biholar, K. Lucas, J. Proctor, and E. Woller for assistance in training and/or testing the animals. We also thank T. Cauller, W. Barnes, and $\mathrm{S}$. K. Yi for assistance in preparing the figures and J. Mellott for assistance in the histological preparation of the tissue.

\section{G R A N T S}

This project was supported by grants from the National Science Foundation, National Institute on Deafness and Other Communication Disorders, Canadian Institutes of Health Research, and the Hearing Foundation of Canada.

\section{REFERENCES}

Apter JT. Eye movements following strychninization of the superior colliculus of cats. J Neurophysiol 9: 73-86, 1946.
Batzri-Izraeli R, Kelly JB, Glendenning KK, Masterton RB, Wollberg Z. Auditory cortex of the long-eared hedgehog (Hemiechinus auritus). I. Boundaries and frequency representation. Brain Behav Evol 36: 237-248, 1990.

Beaver BV, Reed W, Leary S, McKiernan B, Bain F, Schultz R, Bennett BT, Pascoe P, Shull E, Cork LC, Francis-Floyd R, Amass KD, Johnson RJ, Schmidt RH, Underwood W, Thornton GW, Kohn B. 2000 Report of the American Veterinary Medical Association Panel on Euthanasia. J Am Vet Med Assoc 218: 669-696, 2001.

Beitel RE, Kaas JH. Effects of bilateral and unilateral ablation of auditory cortex in cats on the unconditioned head orienting response to acoustic stimuli. J Neurophysiol 70: 351-369, 1993.

Beneyto M, Winer JA, Larue DT, Prieto JJ. Auditory connections and neurochemistry of the sagulum. J Comp Neurol 401: 329-351, 1998.

Bizley JK, Nodal FR, Nelken I, King AJ. Functional organization of ferret auditory cortex. Cereb Cortex 15: 1637-1653, 2005.

Bowman EM, Olson CR. Visual and auditory association areas of the cat's posterior ectosylvian gyrus: cortical afferents. J Comp Neurol 272: 30-42, 1988a.

Bowman EM, Olson CR. Visual and auditory association areas of the cat's posterior ectosylvian gyrus: thalamic afferents. J Comp Neurol 272: 15-29, 1988 b.

Casseday JH, Diamond IT. Symmetrical lateralization of function in the auditory system of the cat: effects of unilateral ablation of cortex. Ann NY Acad Sci 299: 255-263, 1977.

Clarey JC, Irvine DRF. Auditory response properties of neurons in the anterior ectosylvian sulcus of the cat. Brain Res 386: 12-19, 1986.

Clascá F, Llamas A, Reinoso-Suárez F. Insular cortex and neighboring fields in the cat: a redefinition based on cortical microarchitecture and connections with the thalamus. J Comp Neurol 384: 456-482, 1997.

Clascá F, Llamas A, Reinoso-Suárez F. Cortical connections of the insular and adjacent parieto-temporal fields in the cat. Cereb Cortex 4: 371-399, 2000.

Clemo HR, Stein BE. Somatosensory cortex: a "new" somatotopic representation. Brain Res 235: 162-168, 1982.

Dewson JH 3rd, Pribram KH, Lynch JC. Effects of ablations of temporal cortex upon speech sound discrimination in the monkey. Exp Neurol 24: $579-591,1969$.

Doron NN, Ledoux JE, Semple MN. Redefining the tonotopic core of rat auditory cortex: physiological evidence for a posterior field. J Comp Neurol 453: 345-360, 2002.

Girden E. Cerebral determinants of auditory localization. Am J Psychol 52: $1-15,1939$.

Gonzalez-Lima F. Brain imaging of auditory functions in cats: studies with fluoroxyglucose autoradiography and cytochrome oxidase. In: Advances in Metabolic Mapping Techniques for Brain Imaging of Behavioral and Learning Functions, edited by Gonzalez-Lima F, Finkenstaedt T, Scheich H. Dordrecht, The Netherlands: Kluwer Academic, 1992.

Harrington IA, Heffner RS, Heffner HE. An investigation of sensory deficits underlying the aphasia-like behavior of macaques with auditory cortex lesions. Neuroreport 12: 1217-1221, 2001.

Harting JK, Updyke BV, Van Lieshout DP. Cortical projections in the cat: anterograde transport studies of twenty-five cortical areas. J Comp Neurol 324: $379-414,1992$.

Heffner HE. Effect of auditory cortex ablation on localization and discrimination of brief sounds. J Neurophysiol 41: 963-976, 1978.

Heffner HE. The role of macaque auditory cortex in sound localization. Acta Otolaryngol 532: 22-27, 1997.

Heffner HE. The neurobehavioral study of auditory cortex. In: The Auditory Cortex: A Synthesis of Human and Animal Research, edited by König R, Heil P, Budinger E, Scheich H. Mahwah, NJ: Erlbaum, 2005, p. 111-126.

Heffner HE, Heffner RS. Effect of unilateral and bilateral auditory cortex lesions on the discrimination of vocalizations by Japanese macaques. $\mathrm{J} \mathrm{Neu}$ rophysiol 56: 683-701, 1986.

Heffner HE, Heffner RS. Effect of bilateral auditory cortex lesions on sound localization in Japanese macaques. J Neurophysiol 64: 915-931, 1990.

Heffner HE, Masterton B. Contribution of auditory cortex to sound localization in the monkey (Macaca mulatto). J Neurophysiol 38: 1340-1358, 1975.

Heffner HE, Masterton B. Contribution of auditory cortex to hearing in the monkey (Macaca mulatta). In: Recent Advances in Primatology: Behaviour, edited by Chivers DJ, Herbert J. New York: Academic Press, 1978, vol. 1, p. $735-754$. 
Heil P, Irvine DR. Functional specialization in auditory cortex: responses to frequency-modulated stimuli in the cat's posterior auditory field. J Neurophysiol 79: 3041-3059, 1998.

Hess WR, Bürgi S, Bucher V. Motorische Funktion des tektal und tegmental Gebietes. Monatschr Psychiat Neurol 112: 1-52, 1946.

Horikawa K, Kinjo N, Stanley LC, Powell EW. Topographic organization and collateralization of the projections of the anterior and laterodorsal thalamic nuclei to cingulate areas 24 and 29 in the rat. Neurosci Res 6 : 31-44, 1988.

Horsley V, Clarke RH. The structure and function of the cerebellum examined by a new method. Brain 31: 45-124, 1908.

Imig TJ, Reale RA, Brugge JF. The auditory cortex: patterns of corticocortical projections related to physiological maps in the cat. In: Multiple Auditory Areas, edited by Woolsey CN. Clifton, NJ: Humana Press, vol. 3, 1982.

Jenkins WM, Masterton RB. Sound localization: effects of unilateral lesions in central auditory system. J Neurophysiol 47: 987-1016, 1982.

Jenkins WM, Merzenich MM. Role of cat primary auditory cortex for sound-localization behavior. J Neurophysiol 52: 819-847, 1984.

Jiang W, Jiang H, Stein BE. Two corticotectal areas facilitate multisensory orientation behavior. J Cogn Neurosci 8: 1240-1255, 2002.

Jiang W, Wallace MT, Jiang H, Vaughan JW, Stein BE. Two cortical areas mediate multisensory integration in superior colliculus neurons. J Neurophysiol 2: 506-522, 2001.

Kavanagh GL, Kelly JB. Midline and lateral field sound localization in the albino rat (Rattus norvegicus). Behav Neurosci 100: 200-205, 1986.

Kavanagh GL, Kelly JB. Contribution of auditory cortex to sound localization by the ferret (Mustela putorius). J Neurophysiol 57: 1746-1766, 1987.

Kelly JB. Effects of auditory cortical lesions on sound localization by the rat. J Neurophysiol 44: 1161-1174, 1980.

Kelly JB, Glazier SJ. Auditory cortex lesions and discrimination of spatial location by the rat. Brain Res 145: 315-321, 1978.

Kelly JB, Kavanagh GL. Effects of auditory cortical lesions on pure-tone sound localization by the albino rat. Behav Neurosci 100: 569-575, 1986.

Kelly JB, Whitfield IC. Effects of auditory cortical lesions on discriminations of rising and falling frequency-modulated tones. J Neurophysiol 34: 802816, 1971.

Kelly JP, Wong D. Laminar connections of the cat's auditory cortex. Brain Res 212: 1-15, 1981.

Knight PL. Representation of the cochlea within the anterior auditory field (AAF) of the cat. Brain Res 130: 447-467, 1977.

Loftus WC, Sutter ML. Spectrotemporal organization of excitatory and inhibitory receptive fields of cat posterior auditory field neurons. J Neurophysiol 86: 475-491, 2001.

Lomber SG. The advantages and limitations of permanent or reversible deactivation techniques in the assessment of neural function. $J$ Neurosci Methods 86: 109-117, 1999.

Lomber SG, Payne BR. Translaminar differentiation of visually-guided behaviors revealed by restricted cerebral cooling deactivation. Cereb Cortex 10: 1066-1077, 2000.

Lomber SG, Payne BR. Cerebral areas mediating visual redirection of gaze: cooling deactivation of 15 loci in the cat. J Comp Neurol 474: 190-208, 2004.

Lomber SG, Payne BR, Cornwell P. Role of superior colliculus in analyses of space: superficial and intermediate layer contributions to visual orienting, auditory orienting, and visuospatial discriminations during unilateral and bilateral deactivations. J Comp Neurol 441: 44-57, 2001.

Lomber SG, Payne BR, Horel JA. The cryoloop: an adaptable reversible cooling deactivation method for behavioral or electrophysiological assessment of neural function. J Neurosci Methods 86: 179-194, 1999.

Malhotra S, Hall AJ, Lomber SG. Cortical control of sound localization in the cat: unilateral cooling deactivation of 19 cerebral areas. J Neurophysiol 92: 1625-1643, 2004.

Manger PR, Engler G, Moll CK, Engel AK. The anterior ectosylvian area of the ferret: a homologue for an enigmatic visual cortical area of the cat? Eur J Neurosci 22: 706-714, 2005.

Massopust LC Jr, Wolin LR, Frost V. Increases in auditory middle frequency discrimination threshold after cortical ablations. Exp Neurol 28: 299-305, 1970 .

Masterton RB, Diamond IT. Effects of auditory cortex ablation on discrimination of small binaural time differences. J Neurophysiol 27: 15-36, 1964.

Masterton RB, Jane JA, Diamond IT. Role of brain-stem auditory structures in sound localization. I. Trapezoid body, superior olive, and lateral lemniscus. J Neurophysiol 30: 341-359, 1967.
Masterton RB, Jane JA, Diamond IT. Role of brain-stem auditory structures in sound localization. II. Inferior colliculus and its brachium. J Neurophysiol 31: 96-108, 1968.

Meredith MA, Clemo HR. Auditory cortical projection from the anterior ectosylvian sulcus (field AES) to the superior colliculus in the cat: an anatomical and electrophysiological study. J Comp Neurol 289: 687-707, 1989.

Merzenich MM, Brugge JF. Representation of the cochlear partition of the superior temporal plane of the macaque monkey. Brain Res 50: 275-296, 1973.

Middlebrooks JC, Knudsen EI. A neural code for auditory space in the cat's superior colliculus. J Neurosci 10: 2621-2634, 1984.

Middlebrooks JC, Xu L, Furukawa S, Macpherson EA. Cortical neurons that localize sounds. Neuroscientist 8: 73-83, 2002.

Middlebrooks JC, Zook JM. Intrinsic organization of the cat's medial geniculate body identified by projections to binaural response-specific bands in the primary auditory cortex. J Neurosci 1: 203-224, 1983.

Morel A, Garraghty PE, Kaas JH. Tonotopic organization, architectonic fields, and connections of auditory cortex in macaque monkeys. J Comp Neurol 335: 437-459, 1993.

Mori A, Fuwa T, Kawai A, Yoshimoto T, Hiraba Y, Uchiyama Y, Minejima T. The ipsilateral and contralateral connections of the fifth somatosensory area (SV) in the cat cerebral cortex. Neuroreport 7: 23852387, 1996.

Mucke L, Norita M, Benedek G, Creutzfeldt O. Physiologic and anatomic investigation of a visual cortical area situated in the ventral bank of the anterior ectosylvian sulcus of the cat. Exp Brain Res 46: 1-11, 1982.

Neff WD. Localization and lateralization of sound in space. In: Ciba Foundation Symposium on Hearing Mechanisms in Vertebrates, edited by de Reuch AVS, Knight J. London: Churchill, 1968, p. 207-231.

Neff WD, Diamond IT, and Casseday JH. Behavioral studies of auditory discrimination: central nervous system. In: Handbook of Sensory Physiology. Auditory System, edited by Keidel WD, Neff WD. New York: SpringerVerlag, 1975, vol. V2, p. 307-400.

Neff WD, Fisher JD, Diamond IT, Yela M. Role of auditory cortex in discrimination requiring localization of sound in space. J Neurophysiol 19: 500-512, 1956.

Niimi K, Matsuoka H. Thalamocortical organization of the auditory system in the cat studied by retrograde and axonal transport of horseradish peroxidase. Adv Anat Embryol Cell Biol 57: 1-56, 1979.

Olson CR, Graybiel AM. An outlying visual area in the cerebral cortex of the cat. Prog Brain Res 58: 239-245, 1983.

Olson CR, Graybiel AM. Ectosylvian visual area of the cat: location, retinotopic organization, and connections. J Comp Neurol 261: 277-294, 1987.

Palmer AR, King AJ. The representation of auditory space in the mammalian superior colliculus. Nature 299: 248-249, 1982.

Paula-Barbosa MM, Feyo PB, Sousa-Pinto A. The association connexions of the suprasylvian fringe (SF) and other areas of the cat auditory cortex. Exp Brain Res 23: 535-554, 1975.

Payne BR, Lomber SG. Age dependent modification of cytochrome oxidase activity in the cat dorsal lateral geniculate nucleus following removal of primary visual cortex. Vis Neurosci 13: 805-816, 1996.

Payne BR, Lomber SG. A method to assess the functional impact of cerebral connections on target populations of neurons. J Neurosci Methods 86: 195-208, 1999.

Phillips DP, Irvine DR. Properties of single neurons in the anterior auditory field (AAF) of cat cerebral cortex. Brain Res 248: 237-244, 1982.

Phillips DP, Orman SS. Responses of single neurons in posterior field of cat auditory cortex to tonal stimulation. J Neurophysiol 51: 147-163, 1984.

Phillips DP, Reale RA, Brugge JF. Stimulus processing in the auditory cortex. In: Neurobiology of Hearing: The Central Auditory System, edited by Altschuler RA, Bobbin RP, Clopton BM, Hoffman DW. New York: Raven Press, 1991, p. 335-365.

Phillips DP, Semple MN, Kitzes LM. Factors shaping the tone level sensitivity of single neurons in posterior field of cat auditory cortex. J Neurophysiol 73: 674-686, 1995.

Populin LC, Yin TCT. Behavioral studies of sound localization in the cat. J Neurosci 6: 2147-2160, 1998.

Rauschecker JP. Compensatory plasticity and sensory substitution in the cerebral cortex. Trends Neurosci 18: 36-43, 1995.

Rauschecker JP. Parallel processing in the auditory cortex of primates. Audiol Neurootol 3: 86-103, 1998. 
Rauschecker JP, Kniepert U. Auditory localization behaviour in visually deprived cats. Eur J Neurosci 6: 149-160, 1994.

Rauschecker JP, Korte M. Auditory compensation for early blindness in cat cerebral cortex. J Neurosci 13: 4538-4548, 1993.

Rauschecker JP, Tian B, Pons T, Mishkin M. Serial and parallel processing in rhesus monkey auditory cortex. J Comp Neurol 382: 89-103, 1997.

Ravizza R, Diamond IT. Role of auditory cortex in sound localization: a comparative ablation study of hedgehog and bushbaby. Fed Proc 33: 1917-1919, 1974

Ravizza R, Masterton B. Contribution of neocortex to sound localization in opossum (Didelphis virginiana). J Neurophysiol 35: 344-356, 1972.

Read HL, Winer JA, Schreiner CE. Functional architecture of auditory cortex. Curr Opin Neurobiol 12: 433-440, 2002.

Reale RA, Imig TJ. Tonotopic organization in auditory cortex of the cat. J Comp Neurol 192: 265-291, 1980.

Reinoso-Suárez F. Topographical Atlas of the Cat Brain for ExperimentalPhysiological Research [in German]. Darmstadt, Germany: Merck, 1961.

Ribaupierre $\mathbf{F}$ de. Acoustical information processing in the auditory thalamus and cerebral cortex. In: The Central Auditory System, edited by Ehret G, Romand R. New York: Oxford Univ. Press,

Riss W. Effect of bilateral temporal cortical ablation on discrimination of sound direction. J Neurophysiol 22: 374-384, 1959.

Rose JE. The cellular structure of the auditory region of the cat. J Comp Neurol 91: 409-440, 1949.

Sally SL, Kelly JB. Organization of auditory cortex in the albino rat: sound frequency. J Neurophysiol 59: 1627-1638, 1988.

Sanides F, Hoffman J. Cyto- and myelo-architecture of the visual cortex of the cat and of the surrounding integration cortices. J Hirnforsch 11: 79-104, 1969.

Smith AL, Parsons CH, Lanyon RG, Bizley JK, Akerman CJ, Baker GE, Dempster AC, Thompson ID, King AJ. An investigation of the role of auditory cortex in sound localization using muscimol-releasing Elvax. Eur J Neurosci 19: 3059-3072, 2004.

Sousa-Pinto A. The structure of the first auditory cortex (AI) in the cat. I. Light microscope observations on its structure. Arch Ital Biol 111: 112-137, 1973.

Stecker GC, Mickey BJ, Macpherson EA, Middlebrooks JC. Spatial sensitivity in field PAF of cat auditory cortex. J Neurophysiol 89: 28892903, 2003.

Strominger NL. Subdivisions of auditory cortex and their role in localization of sound in space. Exp Neurol 24: 348-362, 1969a.
Strominger NL. Localization of sound in space after unilateral and bilateral ablation of auditory cortex. Exp Neurol 25: 521-533, 1969b.

Thomas H, Tillein J, Heil P, Scheich H. Functional organization of auditory cortex in the Mongolian gerbil (Meriones unguiculatus). I. Electrophysiological mapping of frequency representation and distinction of fields. Eur J Neurosci 5: 882-897, 1993.

Thompson GC, Cortez AM. The inability of squirrel monkeys to localize sound after unilateral ablation of auditory cortex. Behav Brain Res 8: 211-216, 1983.

Thompson GC, Masterton RB. Brain stem auditory pathways involved in reflexive head orientation to sound. J Neurophysiol 41: 1183-1202, 1978.

Thompson RF, Welker WI. Role of auditory cortex in reflex head orientation by cats to auditory stimuli. J Comp Physiol Psychol 56: 996-1002, 1963.

Tian B, Rauschecker JP. Processing of frequency-modulated sounds in the cat's posterior auditory field. J Neurophysiol 79: 2629-2642, 1998.

Tortelly A, Reinoso-Suárez F, Llamas A. Projections from non-visual cortical areas to the superior colliculus demonstrated by retrograde transport of HRP in the cat. Brain Res 188: 543-549, 1980.

Updyke BV. Retinotopic organization within the cat's posterior suprasylvian sulcus and gyrus. J Comp Neurol 246: 265-280, 1986.

Wegener JG. Auditory brain discrimination behavior of brain damaged monkeys. J Audit Res 4: 227-254, 1964.

Whitfield IC. Auditory cortex and the pitch of complex tones. J Acoust Soc Am 67: 644-647, 1980.

Whitfield IC, Cranford J, Ravizza R, Diamond IT. Effects of unilateral ablation of auditory cortex in cat on complex sound localization. J Neurophysiol 35: 718-731, 1972.

Winer JA. The functional architecture of the medial geniculate body and primary auditory cortex. In: The Mammalian Auditory Pathway: Neuroanatomy, edited by Webster DB, Popper AN, Fay RE. New York: SpringerVerlag, 1992, p. 222-409.

Woolsey CN. Organization of cortical auditory system: a review and synthesis. In: Neural Mechanisms of the Auditory and Vestibular Systems, edited by Rasmussen GL, Windle WF. Springfield, IL: C. C Thomas, 1960.

Woolsey CN. Organization of cortical auditory system. In: Sensory Communication, edited by Rosenblith WA. Cambridge, MA: MIT Press, 1961, p. 235-257.

Woolsey CN, Walzl EM. Topical projection of nerve fibers from local regions of the cochlea to the cerebral cortex of the cat. Bull Johns Hopkins Hosp 71: 315-344, 1942. 